\title{
Sex Differences in the Effects of Sertraline and Stressors in Rats Previously Exposed to Restraint Stress
}

\author{
Inês Pereira-Figueiredo', Juan Carro1,2, Luis J. Muñoz ${ }^{3}$, Consuelo Sancho1, \\ Orlando Castellano ${ }^{1,4}$, Ricardo Gómez-Nieto1,4, Dolores E. López ${ }^{1,4}$ \\ ${ }^{1}$ Neuroscience Institute of Castilla y León/IBSAL, University of Salamanca, Salamanca, Spain \\ ${ }^{2}$ Department of Basic Psychology, Psychobiology and Methodology, University of Salamanca, Salamanca, Spain \\ ${ }^{3}$ Animal Research Service, University of Salamanca, Salamanca, Spain \\ ${ }^{4}$ Department of Cell Biology and Pathology, University of Salamanca, Salamanca, Spain \\ Email: lopezde@usal.es
}

Received 13 May 2015; accepted 27 June 2015; published 1 July 2015

Copyright (C) 2015 by authors and Scientific Research Publishing Inc.

This work is licensed under the Creative Commons Attribution International License (CC BY).

http://creativecommons.org/licenses/by/4.0/

c) (i) Open Access

\section{Abstract}

The serotonergic system in the brain plays a major role in mood and anxiety regulation when exposed to stress. The aim of the present study was to evaluate the effects of Sertraline administration in coping with stress using the behavioural paradigms of the acoustic startle reflex (ASR) and its prepulse inhibition (PPI) in both sexes. Wistar rats were divided into two groups: intact animals and exposed to restraint stress (RS) 3 times per day during 7 days, which were then subdivided into three other groups: injected with Sertraline $(5 \mathrm{mg} / \mathrm{kg} / \mathrm{day})$ or the drug vehicle saline for 8 consecutive days, and non-injected. ASR and PPI values were analyzed along 4 sessions to determine behavioral changes. Upon it, we also determine the effects of acute immobilization stress analyzing physiological stress indicators in blood. Our data show sex differences in response to stress paradigms. RS affected more intensely males than females, disturbing the males' growth and the long-term startle habituation that were not affected in females. PPI increased in the vehicle-injected animals when compared to baseline in both sexes, and Sertraline reversed more efficiently it in females. Moreover, despite both sexes exposed to stressful paradigms exhibited a significant increase in serum glutamic-oxaloacetic transaminase and lactate dehydrogenase enzymes when compared with intact controls, as well as leucopenia, some differences according to sex were found in the haemostatic response to stress. Notably, the repeated injections procedure disturbed the early response to stress, which Sertraline only attenuated in both sexes. Our data suggest that 8-day Sertraline administration is effective in reversing stress-induced changes in some physiological parameters, but insufficient to return immunological values to normality. 
Keywords

Behavior, Habituation, PPI, Serotonin, Startle

\section{Introduction}

Our current understanding of the deleterious effects of stress, affecting many other physiological systems besides the brain, is raising increasing concern. Stress is an ambiguous term, as regards its labeling as protective or damaging. The early response to a stressor is protective; the body responds to a sudden unexpected event and many chemical mediators (such as glucocorticoids, catecholamines, and pro and anti-inflammatory cytokines) are released. It is in this way that the organism starts to cope with the situation [1]. However, as is very often the case in life, if the stress condition is prolonged then physiological [2] [3] or psychological changes may be induced [4], as a consequence of the persistent increase in the levels of the same mediators, opening a window which may lead to diseases (among others, coronary heart disease, hypertension, type 2 diabetes, atherosclerosis, obesity), as well as depression, or generalized anxiety disorders [2] [5]-[7]. In light of this, over the past few years several authors have attempted to unveil how organisms manage to mediate the effects of stress [4] [8]-[10].

Both animals and humans are able to develop intrinsic adaptive changes when exposed to stress. A typical form of adaptation is habituation [10]-[12]; this happens when an individual is repeatedly exposed to the same type of stimuli, the responses to these gradually becoming reduced [13]. Another is the ability to achieve irrelevant sensory stimuli, the responses to these gradually being suppressed [14]. A common operational model of this latter is prepulse inhibition (PPI) - a form of plasticity of the startle reflex [15]—in which the startle, induced by an intense startling stimulus that evokes a whole-body reflective response, can be inhibited by prior presentation of a weaker stimulus [16].

According to the literature, both the acoustic startle reflex (ASR) and its modulation (such as the startle habituation and the PPI) are very often used as behavioral tests for the assessment of emotional status in animals and humans [17], and may well be disturbed in many psychiatric disorders [18]-[20] such as anxiety [19], panic disorder [21], or obsessive compulsive disorder [22]. Thus, disruption of the ASR may reflect functional abnormalities in cognitive processes and lead to difficulties in adapting to subsequent stressors [19] [23] [24]. In this respect, the first goal of our work was to check the early and immediate changes induced by restraint stress on disturbing the startle response and it modulation in young rats.

Restraint stress is a very simple animal model extensively used in stress studies with rodents whose effects mimic the above-described pathophysiologic disorders [24]-[27]. The animals must be repeatedly placed in Plexiglas tubes, restricting their movements. The method is straightforward and painless and is assumed to leave no lasting debilitation [28]. However, even though the method is fairly gentle, animals exposed to restraint exhibit alterations in multiple brain structures and behavioral functions that have been proposed to be tightly linked to dysfunctional changes in the serotoninergic system [27] [29] [30]. Among all the monoamines found in the brain, serotonin (5-HT) plays an important role in the processes of the early brain development [31] [32], and it is mainly involved in processes of arousal, vigilance, anxiety, mood and impulsiveness [26]. In this sense, startle and sensorimotor measurements have been suggested to be sensitive to the serotonin balance [33]-[37], which may be disturbed in stressed animals [38]. Currently, the main drugs employed for the management of anxiety disorders are 5-HT reuptake inhibitors [29] [39]. In light of this, we speculated that by dispensing Sertraline (SERT), a selective serotonin reuptake inhibitor (SSRI) to young rats we would be able to mediate stress-induced changes in behavioral models. Also, considering the crucial role of 5-HT in the physiological response to stress [40] [41], our main goal was to examine the effects of SERT treatment (via the intraperitoneal route) in previously restrained animals, when these are subjected to a new stressor, the immobilization stress (IMO). Giving the significant body of evidence regarding stress and sex on later behavior [28] [42]-[44], and the sex-dependent response to antidepressants in several species [45] [46], analyses were made simultaneously for male and female rats.

\section{Materials and Methods}

\subsection{Animal Experiment}

Highly outbred male and female Wistar rats of 70 - 72 days of age (respectively weighing 290 - $310 \mathrm{~g}$ and 170 - 
$185 \mathrm{~g}$ at the beginning of the experiment) were provided by our own animal facility at the University of Salamanca. Rats were housed and maintained on a 12:12 hour light: dark cycle (lights on at 8 am) in a room with controlled temperature.

For all experiments, the animals were allowed access to food and water ad libitum, and were maintained on a regular light-dark cycle (lights on: 07:00am - 19:00pm) with constant temperature $\left(21^{\circ} \mathrm{C}\right)$. The animals were handled and cared for according to the guidelines of the European Community's Council Directive (2010/63/CE) and current Spanish legislation for the care and use of laboratory animals.

\subsection{Determination Startle and Prepulse Inhibition}

The acoustic startle reflex was measured in six identical startle-response cages, using the SR-LAB system (SDI, San Diego, CA, USA). Acoustic stimulus intensities and response sensitivities were calibrated (using an SRLAB Startle Calibration System) so that they would be nearly identical in each of the six SR-LAB systems (maximum variability $<1 \%$ of stimulus range and $<5 \%$ of response ranges). Each testing session consisted of an acclimatization period of $\sim 5$ min, followed by 64 trials presented pseudo-randomly, with a mean inter-trial interval of $30 \mathrm{~s}$, as previously described [47]. Briefly, the sessions had four blocks of pulse and prepulse, with prepulse-to-pulse intervals of 50ms. Whole-body movements corresponding to startle responses were recorded and analyzed with the SR-LAB system, providing ASR latencies and amplitudes. The background noise of 65 $\mathrm{dB}$ SPL was generated throughout the entire session in order to avoid interference from external noise and to ensure equal experimental conditions. As depicted in the experimental design (Figure 1), four sessions of startle and sensory motor gating were performed in all animals. Before testing, the rats were habituated to the experimental conditions, especially regarding their introduction into the ASR device. All testing was carried out between 10:00 and 13:00 hours [48].

Experiment 1

$\stackrel{n}{\frac{\pi}{0}}$
Experiment 2
Experiment 3

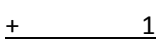

\begin{tabular}{|c|c|c|c|c|c|c|c|}
\hline A & \multirow{3}{*}{ No stress (Control) } & \multirow{2}{*}{$\begin{array}{l}A \\
S \\
R\end{array}$} & \multirow{2}{*}{$\begin{array}{l}A \\
S \\
R\end{array}$} & Control & \multirow{2}{*}{$\begin{array}{l}A \\
S \\
R\end{array}$} & \multirow{4}{*}{ IMO } & \multirow{3}{*}{$\begin{array}{l}\text { o } \\
\text { d }\end{array}$} \\
\hline$S$ & & & & Control+ Veh & & & \\
\hline \multirow{2}{*}{$P$} & & $\mathrm{P}$ & $P$ & Control+ SERT & \multirow{4}{*}{$\begin{array}{l}P \\
P \\
1 \\
4\end{array}$} & & \\
\hline & \multirow{4}{*}{$\begin{array}{l}\text { Restraint stress } \\
\text { ( } 45 \mathrm{~min} / 3 \text { times a day) }\end{array}$} & $\mathrm{P}$ & $\mathrm{P}$ & Previous stress (RS) & & & \\
\hline 1 & & 1 & 1 & & & & $\mathrm{t}$ \\
\hline \multirow{2}{*}{1} & & 2 & 3 & Previous stress (RS+Veh) & & & a \\
\hline & & & & Previous stress ( RS+SERT) & & & e \\
\hline & & & & & & No-IMO & $\mathrm{n}$ \\
\hline
\end{tabular}

Figure 1. Experimental design used for the present study. Experiment 1: the day before starting the protocol of restraint stress (RS, day 0), all animals were subjected to the first behavioral test (ASR/PPI 1) in which basal values were obtained; and the day after the end of RS, a second behavioral test was performed (ASR/PPI 2). Experiment 2: Control or previously stressed animals of both sexes were subdivided into 6 subgroups according to the treatment applied: the animals subjected to 8 days of intraperitoneal (i.p.) injections with vehicle (Control + Veh, RS + Veh), or SERT (SERT: 5 mg/kg/day) (Control + SERT; RS + SERT); and the animals not injected that remained undisturbed (Control, RS). On the first day of experiment 2 , one hour after the i.p. protocol all animals were subjected to the third behavioural test (ASR/PPI 3); and again on the last day, one hour after the i.p. procedure, all animals were subjected to the fourth behavioural test (ASR/PPI 4). Experiment 3: all animals except those subjected to restraint plus the i.p. injections were subjected to a session of immobilization stress (IMO) and 10 min after that, trunk blood samples were taken for comparison with a group of undisturbed controls, subjected only to blood sampling (No-IMO). 
In the first experiment, the effect of the stress was indexed by (Average ASR2/ Average ASR1) $\times 100)-100$ ), giving the percentage (\%) of change in each individual. In the second experiment, long-term change (\%) (LTC) in ASR amplitudes as a result of repeated testing were indexed by (Average ASR4/ Average ASR1) $\times 100$ ) 100, with body weight as a covariate. Thus, a positive and negative LTC respectively indicate the sensitization or habituation of the startle [11]. Immediately after each session, all animals were weighed and all females were subjected to estrous determination.

\subsection{Estrous Cycle Determinations}

Vaginal smears were obtained by dipping a sterile swab (0.6 mm diameter, 0.025 in Fischer Scientific) in sterile saline, and then gently swabbing the vaginal lumen. The swabs were smeared onto labeled glass slides that were previously cleaned with 95\% ethanol. The cells were fixed with 95\% ethanol for 15 minutes and then air-dried before staining with haematoxylin-eosin. The vaginal smears were inspected and the phase of the estrous cycle was determined using an Olympus Microscope $(\times 40)$, and following previous criteria [49], a 4 to 5 day-cycle was considered (proestrus, estrous, metestrus and diestrus). Rats in proestrus with the highest estrogen levels (with high number of nucleated epithelial cells); by contrast, rats in estrus with the lowest estrogen levels (with anucleate cornfield cells) [24] [49]; rats in metestrus with high number of white blood cells (WBC) and nucleated cornified cells; and rats in diestrus having some epithelial cells and still a predominance of WBC. Females were later distributed in order to have an equal number of animals in each phase in each group.

\subsection{Restraint Stress}

The day after the first startle/PPI session, animals of both sexes were placed in an isolated room, where they were distributed to either the restraint stress paradigm $(\mathrm{N}=21$ females and $\mathrm{N}=20$ males) or were left undisturbed (served as controls in the first experiment) ( $\mathrm{N}=19$ females and $\mathrm{N}=22$ males). The rats exposed to restraint (RS) were placed daily in small transparent Plexiglas cylinders, three times a day for 45 minutes along 7 days. This device limited their body movements (the rats were not able to move forward or backward) and was positioned directly under a bright light. The length and diameter of the cylinder were based on body size, smaller-diameter cylinders being used in females than in males (70 vs. $80 \mathrm{~mm}$ ), all with adjustable endplates.

\subsection{Intraperitoneal Protocol}

On the day after the second behavioral session (ASR/PPI 2) and two days after completion of the RS period, all animals of both sexes were subdivided into six subgroups according to the further treatment to be subjected (see Figure 1).

SERT-receiving rats were given Sertraline $\left(\right.$ Besitran $^{\odot}$ Pfizer S.A. Madrid, SPAIN) intraperitoneally at 5 $\mathrm{mg} / \mathrm{kg} /$ day once daily (i.p.) for 8 days. Sertraline was dissolved in $0.9 \% \mathrm{NaCl}$ vehicle and were administrated in a dose of $1 \mathrm{ml} / \mathrm{kg}$. The dose was based on previous reports [50]. Vehicle-injected animals (Control + Veh and RS + Veh) were given $0.9 \%$ saline solution in the same manner. These animals were used in order to control for the stressful effect of the intraperitoneal (i.p.) administration route. Also, two groups of non-injected (RS and Control) animals of both sexes were left undisturbed from the first to the last day of the i.p. procedure, and were used as a control of the experimental conditions.

\subsection{Immobilization Stress}

On the day after the completion of the behavioural tests, all animals were exposed to immobilization stress (IMO), a procedural variation of restraint. The same cylinders that had been used previously were adjusted to achieve total restriction of movements, taking care not to hurt the animal [51]. Each rat was placed in the cylinder for $30 \mathrm{~min}$, after which it was placed in a new cage and allowed to rest for $10 \mathrm{~min}$. Then, the animal was anesthetized and trunk blood was taken by cardiac puncture [50].

This procedure was carried out simultaneously on three animals from 10:00 h to 13:00 h. A group of undisturbed animals (No-IMO) of the same age was also used in order to achieve the effects of IMO stress. In order to reduce the inherent effects of differences in the estrous cycle, only females that were not in proestrus were used [52]. 


\subsection{Hematological Analyses}

For hematological analyses, trunk blood was collected to EDTA (K3)-containing tubes that were freshly processed on an automatic cell counter (ADVIA 120 cytometer, Bayer, Leverkusen, Germany). The obtained hematological parameters were number of erythrocyte, hemoglobin concentration, mean corpuscular hemoglobin (MCH), hematocrit values, platelet number and mean platelet volume (MPV), and the number and type of leukocytes (WBC).

\subsection{Biochemical Analyses}

For biochemical analyses, blood samples were collected into heparinized tubes, which were then centrifuged at $10,000 \times \mathrm{g}$ for $20 \mathrm{~min}$ to obtain serum, which was drawn into Eppendorf tubes and used fresh on a SPOTCHEM $^{\mathrm{TM}}$ EZ device (QBC Europe). The levels of serum total protein (T-Pro), albumin and bilirubin, and the cytosolic enzymes glutamic-oxaloacetic transaminase (GOT), glutamic-pyruvic transaminase (GPT), and lactate dehydrogenase (LDH) were measured using the commercial kit (ARKRAY ${ }^{\circledR}$ ) according to the manufacturer's directions.

\subsection{Statistics}

Statistical analyses were performed using IBM $^{\circledR}$ SPSS $^{\circledR}$ software, version 20 (IBM Crp. and SPSS Inc., Chicago, IL, USA, 2011). Differences between groups were analyzed by ANOVA (one, two and three way), followed by the Fisher-PLSD-test for post hoc comparison if appropriate, and ANOVA mixed (or "SPLIT-PLOT") with the Bonferroni-test. Mean differences were subjected pairwise to Student's t-test, using the Levene Test for equality of variances. Pearson's coefficient was used to determine correlations. Differences were regarded as statistically significant when $p \leq 0.05$.

\section{Results}

\subsection{Experiment 1}

This experiment aimed at obtaining preliminary data regarding the effects of one week of restraint stress on ASR and PPI, measuring the data one day after completion of the stress protocol.

\subsubsection{Startle Amplitude after Stress by Restraint}

The three-way (group $\times$ sex $\times$ day) repeated-measures ANOVA indicated a significant effect of the repeated measurements of startle $\left(\mathrm{F}_{1,74}=5.30, p=0.02\right)$. Post-hoc analyses revealed that a slight increase in the startle reflex with stress was present $\left(F_{1,74}=2.58\right.$, n.s.), but no differences in ASR amplitude between the control and stressed animals of both sexes were significant (Figure 2(a)). As depicted in Figure 2, Figure 2(a) given the huge differences between males and females in this parameter the sex of the animal was a determining factor in the startle response $\left(\mathrm{F}_{1,74}=4.47, p<0.001\right)$.

When the change of the startle amplitudes between sessions was evaluated (using a two-way ANOVA, with group and sex as factors), the analysis confirmed that startle modulation was not significantly altered by stress $\left(\mathrm{F}_{1,74}=1.29\right.$, n.s) despite the control males exhibited an habituation trend (Figure 2(b)).

\subsubsection{Prepulse Inhibition}

No differences in PPI levels as effect of stress were found (Figure 3) in either sex (Figure 3(a)). In overall the males exhibited significantly higher PPI values than the females $\left(\mathrm{F}_{1,74}=70.60, p<0.001\right)$.

Moreover, the repeated measures ANOVA (group $\times$ sex $\times$ day) revealed that PPI increased significantly with respect to its basal values $\left(\mathrm{F}_{1,74}=24.06 p<0.001\right)$, with no interaction with group $\left(\mathrm{F}_{1,74}=1.89\right)$ or $\operatorname{sex}\left(\mathrm{F}_{1,74}=\right.$ 3.89). Post-hoc analysis revealed that the difference in males was significant, regardless of the stress treatment, and in females PPI only increased when the repetitive situation of restraint stress was applied (Figure 3(b)).

\subsubsection{Latencies}

The repeated measures of ANOVA showed no significant changes with the stress procedure in the latency of startle and PPI latency $\left(F_{1,75}=2.17\right.$ and $F_{1,75}=0.021$, respectively). On the day after completion of the stress pro- 


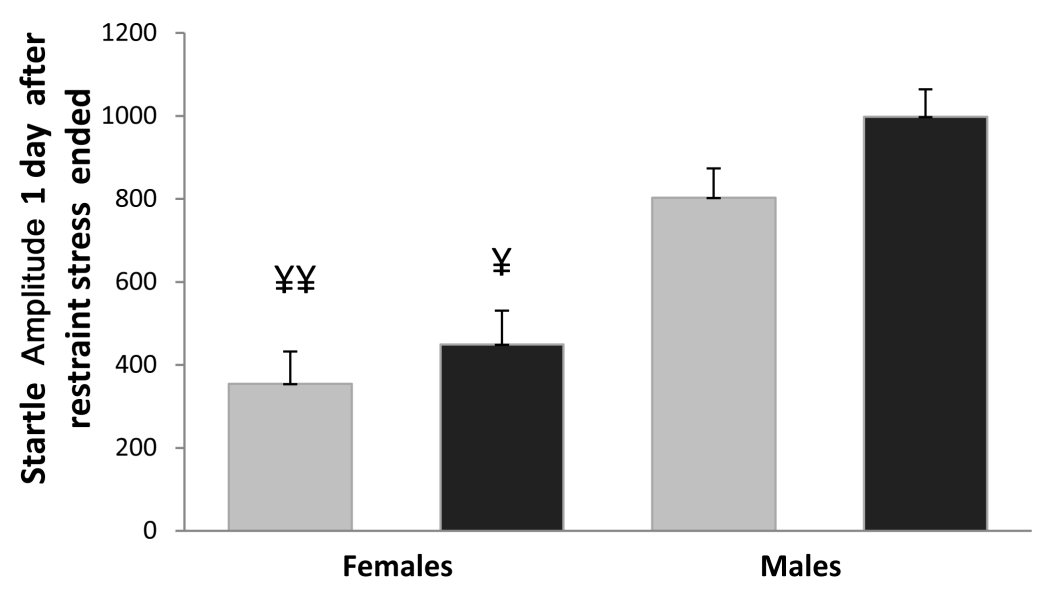

(a)

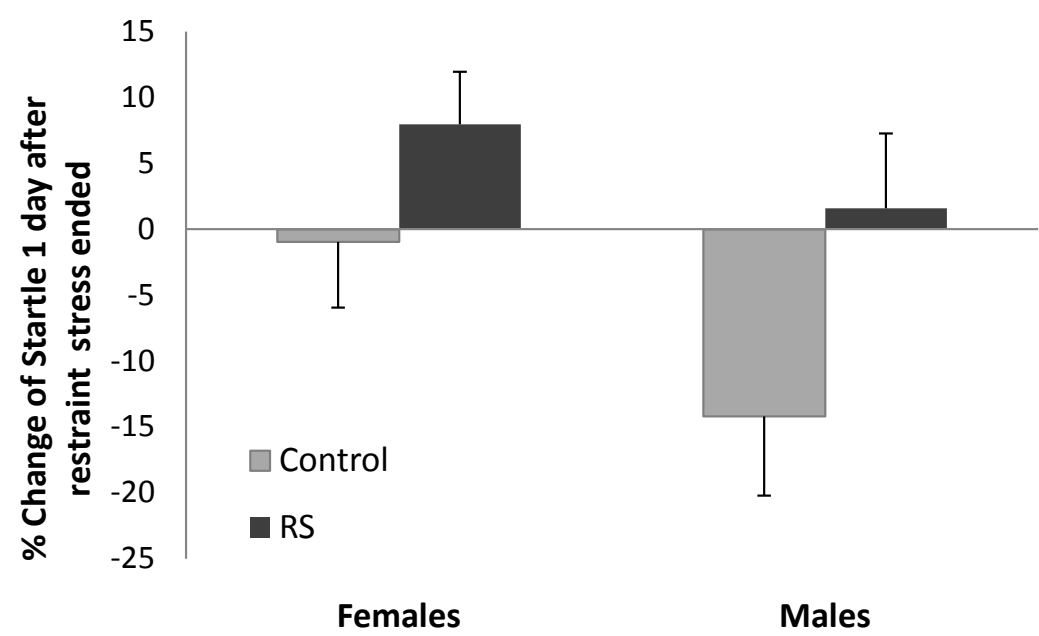

(b)

Figure 2. Acoustic startle reflex (ASR) results of experiment 1. (a) ASR amplitude (in arbitrary units) after 1 week of restraint stress (RS) or no stress (Control); (b) Percentage of change in the startle amplitudes induced by stress in female and male animals, when measured one day after it ended. $\mathrm{N}=17$ 21 animals per group and sex. Each column represent the means \pm standard error (S.E.) ${ }^{\sharp ¥} p<0.01$ and ${ }^{\sharp} p<0.05$ indicate the differences between males and females.

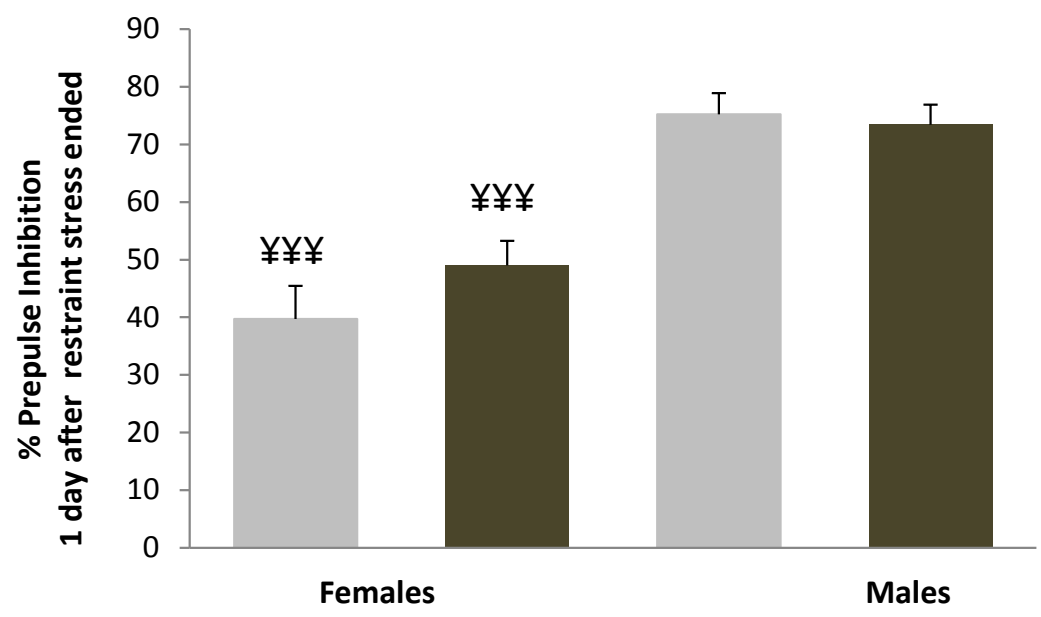

(a) 


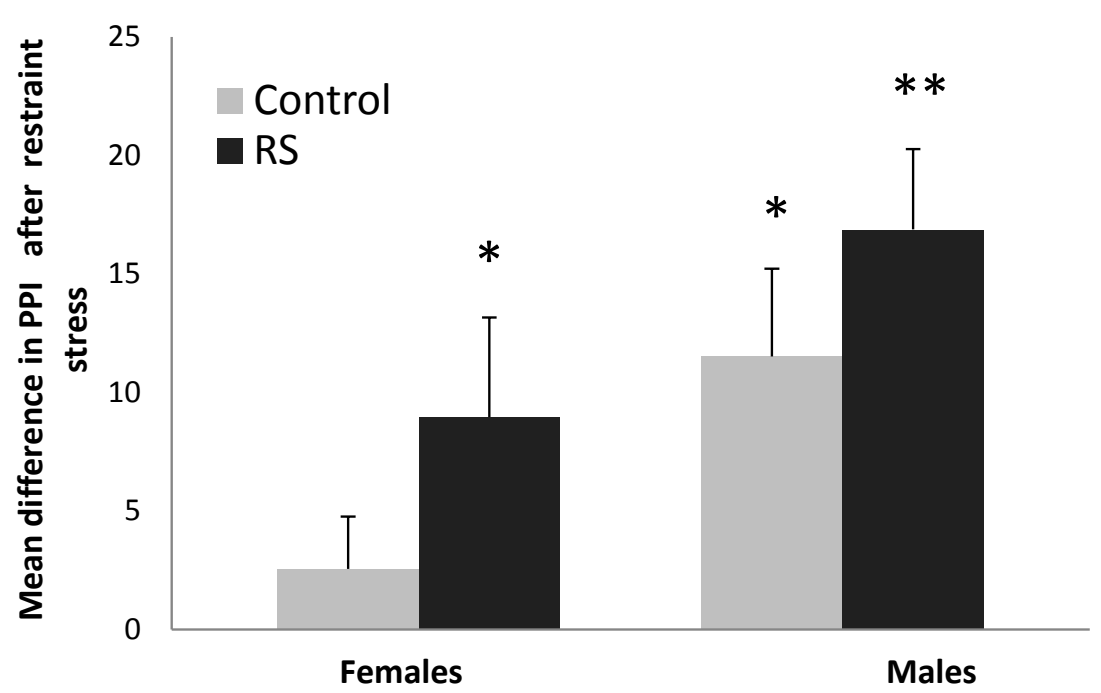

(b)

Figure 3. Percentage of prepulse inhibition (PPI) of experiment 1. (a) Percentage of prepulse inhibition after 1 week of restraint stress (RS) or no stress (Control); (b) The mean differences \pm S.E in the PPI values induced by stress in the animals of both sexes, one day after it ended (when related to baseline). ${ }^{¥ ¥} p<0.01$ indicate the differences between males and females; ${ }^{* *} p<0.01$ and ${ }^{*} p<0.05$, indicate a significant increase of the PPI.

cedure, no differences as an effect of stress were found in either sex. However a group $\times$ sex interaction was revealed $\left(\mathrm{F}_{1,75}=6.5, p=0.013\right)$, meaning that there were differences in the response to stress depending on the animal's sex (Table 1 ).

\subsubsection{Body Weight Variation}

Analyses were made separately for males and females. All animals increased their weight (from PND 70 to PND $78, p<0.001$ ). A two-way ANOVA (group $\mathrm{x}$ day) revealed that restraint stress affected body weight gain in both sexes. When the animals were examined the day after completion of the stress protocol, the RS animals were seen to have gained less weight than their non-stressed counterparts (females $\mathrm{F}_{1,32}=9.32, p=0.005$ and males $\mathrm{F}_{1,44}=50.1, p<0.001$ ) (Figure 4). As shown in Figure 4(a) and Figure 4(b), although the effect of this type of stress on weight gain in both sexes was clear, the difference only reached significance in males $\left(\mathrm{F}_{1,44}=\right.$ $11.8, p<0.01)$.

\subsection{Second Experiment}

This experiment had two main objectives: to examine the effects of one week of restraint stress 10 days after completion of the stress protocol, and to examine the effects of repeated injections (either vehicle or SERT) in previously stressed animals.

\subsubsection{Startle Amplitudes after the Experimental Paradigms}

A three-factor ANOVA with group and sex as between-subject design factors and time as the repeated design factor revealed that a single SERT/vehicle i.p. injection did not affect the startle response $\left(F_{1,62}=0.04\right.$, n.s.), and no differences were found as an effect of group or sex (ASR $\times$ group, $F_{5,62}=0.98$, n.s.; ASR $\times$ sex, $F_{1,62}=0.15$, n.s.). Again, 8 days following the i.p. procedure did not affect ASR amplitude $\left(F_{1,62}=0.26\right.$, n.s. $)$ Also, when the analyses were split by days, no significant differences in the ASR means were observed as an effect of the combined paradigms of restraint stress plus Sertraline/vehicle procedure in either sex $(p>0.05)$. Moreover, clear sex differences in the ASR were found, regardless of the group, $\mathrm{F}_{1,62}=39.7, p<0.001$ (Figure 5).

When the long-term change (\%) (LTC) of the startle was further analyzed (using a two-way ANOVA), no significant differences between groups were found $\left(\mathrm{F}_{5,73}=1.22\right)$, however, both sex $\left(\mathrm{F}_{1,73}=7.43, p=0.008\right)$ and group $\times$ sex, $\left(\mathrm{F}_{5,73}=3.23, \mathrm{p}=0.01\right)$ interactions affected it. 


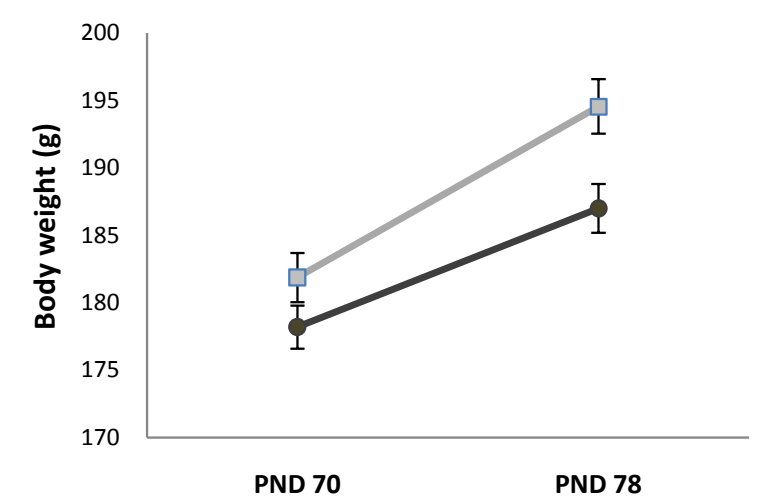

(a)

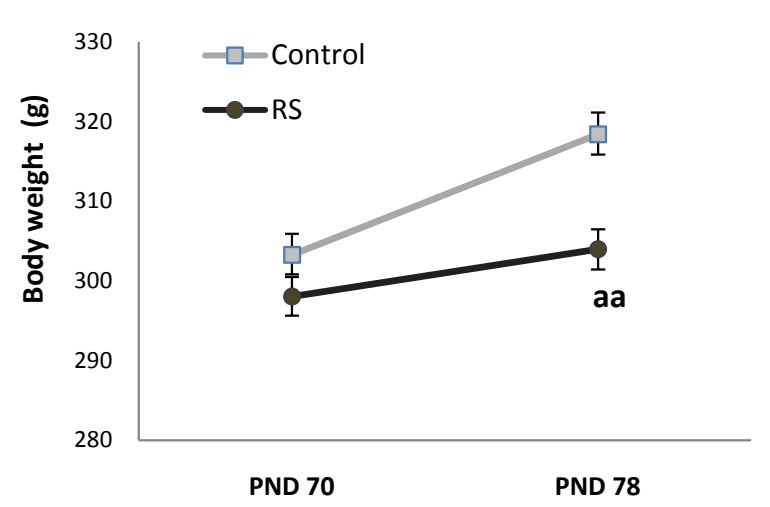

(b)

Figure 4. Body weight gain. Effects of one week of restraint stress on the in female and male animals submitted or not to restraint (RS and Control). Abbreviations: PND 70 and PND 78, postnatal days 70 and 78, respectively; $\mathrm{N}=17$ - 21 animals per group and sex. Mean values \pm S.E. aa indicates a main effect of restraint stress in males. (a) Females; (b) Males.

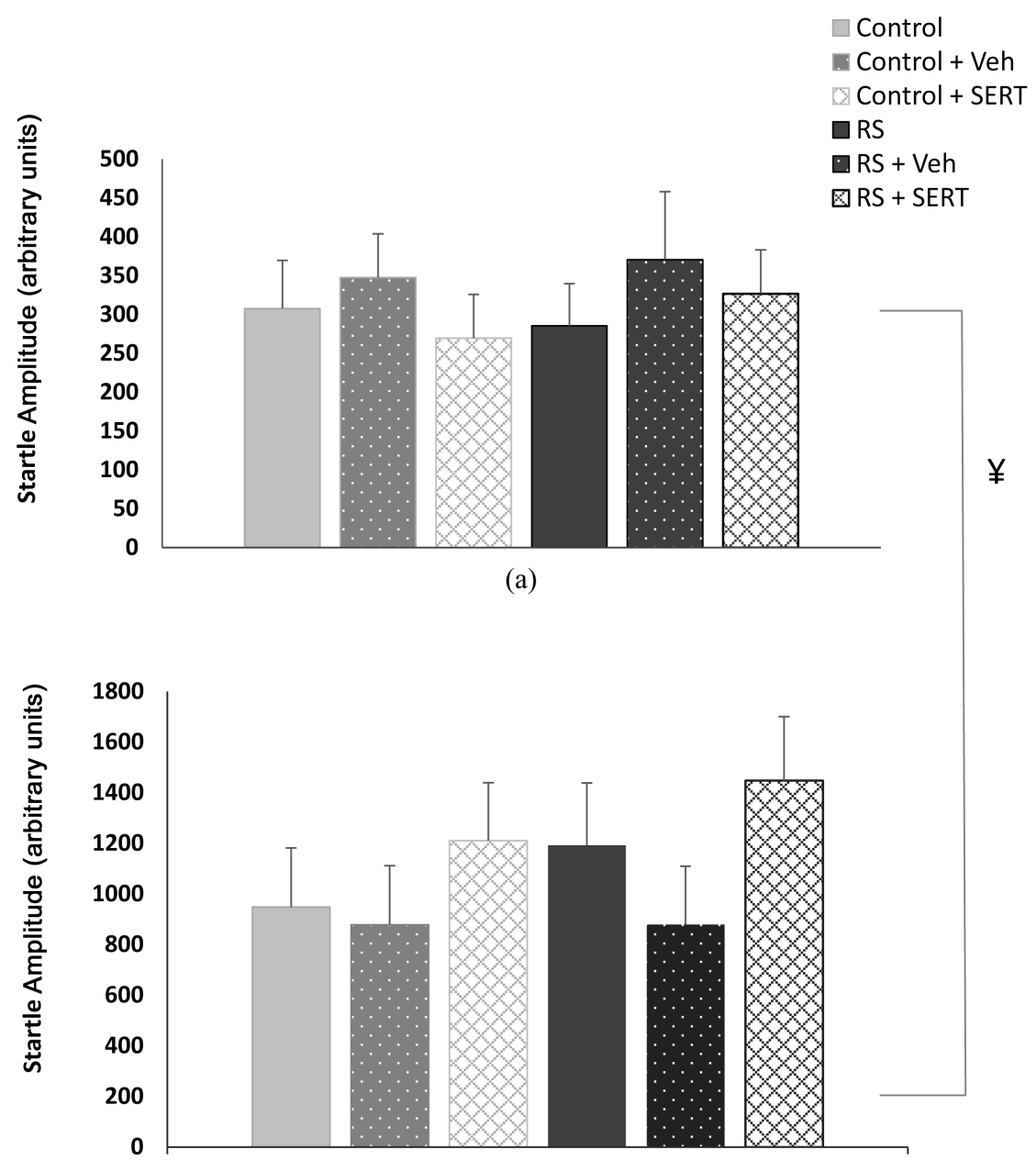

(b)

Figure 5. Acoustic startle reflex (ASR) amplitude of experiment 2. Mean ASR amplitude values (in arbitrary units) in (a) females and (b) males previously stressed/or not stressed by restraint that were further subjected to 8 days of intraperitoneal injections with vehicle (RS + Veh; Control + Veh), SERT (5 mg/kg/day) (RS+SERT CC + SERT), or not injected (Control, RS). Body weight was used as a covariate. $\mathrm{N}=6-8$ animals per group and sex. Mean values $\pm \mathrm{S} . \mathrm{E}$. ${ }^{\sharp} p<0.05$ indicates the significant differences between males and females in all the experimental groups. (a) Females; (b) Males. 
Table 1. Effects of restraint stress on the acoustic startle reflex (ASR) and prepulse inhibition (PPI) latency one day after the end of the stress procedure.

\begin{tabular}{|c|c|c|c|c|c|c|}
\hline \multicolumn{7}{|c|}{ Startle latency } \\
\hline \multirow{3}{*}{$\begin{array}{l}\text { Groups } \\
\text { Control }\end{array}$} & \multicolumn{3}{|c|}{ Females } & \multicolumn{3}{|c|}{ Males } \\
\hline & \multirow{2}{*}{\begin{tabular}{|c|} 
Mean value \\
$31.1 \pm 2.1$
\end{tabular}} & \multicolumn{2}{|c|}{ Difference vs. basal } & \multirow{2}{*}{\begin{tabular}{|c|} 
Mean value \\
$35.3 \pm 1.8$
\end{tabular}} & \multicolumn{2}{|c|}{ Difference vs. basal } \\
\hline & & +0.27 & \pm 2.6 & & -3.52 & \pm 2.3 \\
\hline RS & $30.5 \pm 2.3$ & -1.82 & \pm 3.3 & $36.7 \pm 1.8$ & +0.61 & \pm 1.7 \\
\hline \multicolumn{7}{|c|}{ PPI latency } \\
\hline \multirow[t]{2}{*}{ Groups } & \multicolumn{3}{|c|}{ Females } & \multicolumn{3}{|c|}{ Males } \\
\hline & Mean value & \multicolumn{2}{|c|}{ Difference vs. basal } & Mean value & \multicolumn{2}{|c|}{ Difference vs. basa } \\
\hline Control & $26.9 \pm 1.3^{Y}$ & -0.25 & \pm 1.6 & $28.7 \pm 1.3$ & -2.37 & \pm 2.1 \\
\hline RS & $28.6 \pm 2.1$ & +1.11 & \pm 1.4 & $28.9 \pm 1.1$ & -1.95 & \pm 2.2 \\
\hline
\end{tabular}

Mean values \pm error standard in the different experimental groups ( $\mathrm{N}=6$ - 8 per group). ${ }^{\sharp} p<0.01$ and ${ }^{q} p<0.05$ indicate significant differences between males and females after the experimental procedure; b indicates the main effect of SERT in males vs. Control; ${ }^{*} p<0.05$, indicates the significant decrease of the ASR latency as an effect of the intraperitoneal injections with vehicle in males, when compared to baseline.

Split the analyses by sex, post-hoc shows in males that RS induced a significant increase in ASR amplitudes (in \%), $\mathrm{F}_{5,62}=2.74, p=0.034$ (Figure 6). Previously restrained males exhibited an increase of $65.8 \% \pm 30.7 \%$ amplitude relative to baseline $(p=0.027)$, indicating that these animals had difficulty in becoming accustomed to retesting (Figure 6(b)). In the females, no significant changes in the ASR as an effect of restraint were found $\left(F_{5,62}=0.65\right.$, n.s.), despite, it was marginally affected by the i.p. method, an effect that was inverted by SERT administration (Figure 6(a)).

\subsubsection{Prepulse Inhibition after the Experimental Paradigms}

As seen above, a single i.p. injection did not change PPI $\left(F_{1,61}=1.92\right.$, n.s.). However, repeated SERT/vehicle intraperitoneal injections induced a significant effect on PPI $\left(F_{1,61}=19.92, p<0.001\right)$, with a group $\times$ sex $F_{5,58}=$ 7.2, $\mathrm{p}<0.001$ interaction. Post-hoc analysis revealed that while PPI remained virtually unchanged in the Control and RS animals of both sexes, PPI increased in both groups of vehicle-injected animals (Control + Veh and RS + Veh), regardless of the stress treatment, and SERT reversed this effect (Figure 7) more efficiently in females than in males. Also, a main effect of sex, $\mathrm{F}_{1,58}=122.9$, $p<0.001$ was observed.

\subsubsection{Variation of the Startle Reflex and PPI Latencies}

ASR latency did not change significantly in comparison with the baseline, although the latency of startle $\times$ group $\times$ sex interaction $\left(\mathrm{F}_{5,62}=2.58, p=0.035\right)$ was observed and, again, differences between the sexes were observed $\left(\mathrm{F}_{1,62}=22.2, p<0.001\right)$. Regarding each sex, no significant differences in startle latency were found between the groups $\left(F_{5,62}=0.09\right.$, n.s.); however, a different trend was revealed when its values after the experimental paradigms were compared to baseline figures. Post-hoc analysis revealed that the daily-injection procedure shortened the latency to respond. In males, this effect reached significance, regardless of previous stress, and SERT treatment reversed it in both sexes (Table 2).

Overall, PPI latency did not change significantly when compared with the baseline, $\mathrm{F}_{1,65}=1.56$, n.s., but again, differences depending on sex were apparent, $\mathrm{F}_{1,65}=14.3, p<0.001$. As shown in Table 2, a decrease (although not significant) in PPI latency was observed in previously injected animals of both sexes, an effect that was not reversed by SERT in males. When the analyses were made split by sex and day, after the treatments a main effect of group $\left(\mathrm{F}_{5,65}=4.5, \mathrm{p}=0.001\right)$ was revealed in males, probably as effect of SERT administration, whereas in females differences between the experimental groups reached no significance.

Moreover, an overall dimorphism was observed in both the startle reflex and PPI latency values in the vehicle-injected and restrained animals (data not shown), again indicating a different response to the adverse procedures by each sex. 


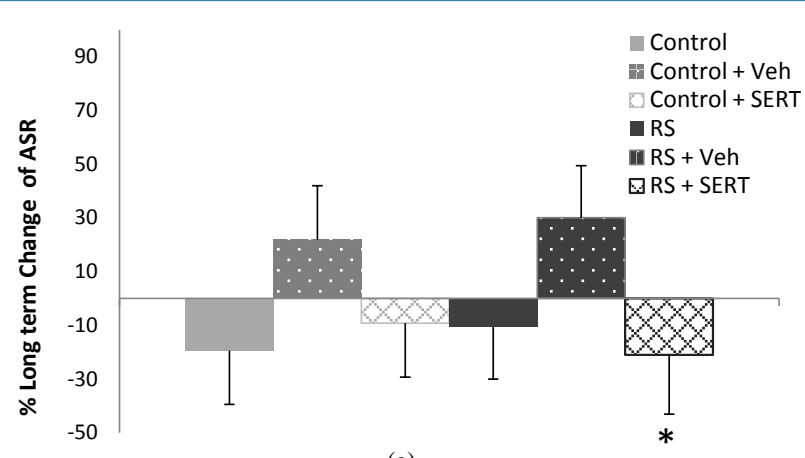

(a)

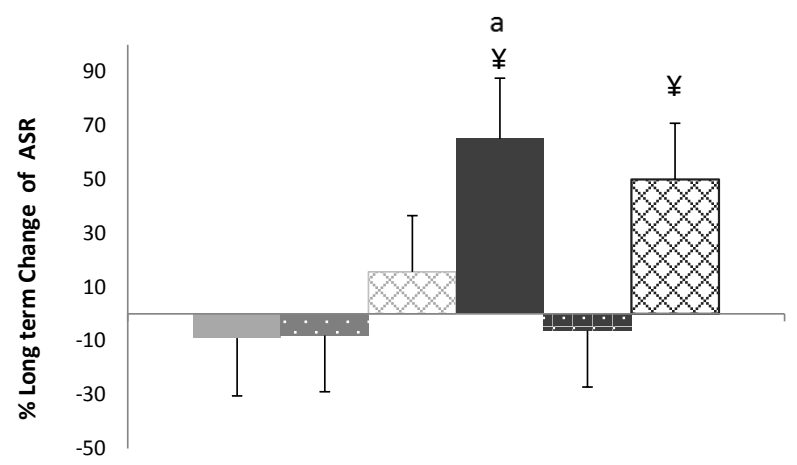

(b)

Figure 6. Long term change of the acoustic startle reflex (ASR) amplitude. Percentage of long-term Change in the startle amplitude induced by the experimental paradigms in (a) females and (b) males. $\mathrm{N}=6-8$ animals per group and sex. Means \pm S.E. ${ }^{*} p<0.05$, indicates a significant decrease of the startle reflex; a $p<0.05$, indicates the main effect of restraint stress in males (RS vs. Control). ${ }^{¥} p<0.05$ indicates significant differences between males and females. (a) Females; (b) Males.

Table 2. Effects of restraint stress + SERT/Vehicle intraperitoneal treatment on the acoustic startle reflex (ASR) and prepulse inhibition (PPI) latency).

\begin{tabular}{|c|c|c|c|c|}
\hline \multicolumn{5}{|c|}{ Startle latency } \\
\hline Experimental groups & \multicolumn{2}{|c|}{ Females } & \multicolumn{2}{|c|}{ Males } \\
\hline & \multicolumn{2}{|c|}{ Mean values \pm s.e. } & \multicolumn{2}{|c|}{ Mean values \pm s.e. } \\
\hline Control & 30.1 & \pm 3.3 & 37.2 & \pm 3.1 \\
\hline Control + Veh & 26.8 & $\pm 3.2^{q}$ & 35.7 & $\pm 3.0^{*}$ \\
\hline Control + SERT & 32.6 & \pm 3.3 & 37.9 & \pm 3.1 \\
\hline RS & 29.5 & $\pm 3.1^{\Psi}$ & 40.7 & \pm 3.3 \\
\hline RS + Veh & 31.0 & \pm 4.5 & 34.6 & $\pm 3.0^{*}$ \\
\hline \multirow[t]{2}{*}{$\mathrm{RS}+\mathrm{SERT}$} & 33.7 & \pm 3.3 & 40.2 & \pm 3.1 \\
\hline & \multicolumn{2}{|c|}{ PPI latency } & & \\
\hline \multirow[t]{2}{*}{ Experimental groups } & \multicolumn{2}{|c|}{ Females } & \multicolumn{2}{|c|}{ Males } \\
\hline & \multicolumn{2}{|c|}{ Mean values \pm s.e. } & \multicolumn{2}{|c|}{ Mean values \pm s.e. } \\
\hline Control & 31.1 & \pm 2.5 & 34.1 & \pm 2.1 \\
\hline Control + Veh & 26.7 & \pm 2.1 & 28.4 & \pm 2.1 \\
\hline Control + SERT & 30.7 & \pm 2.3 & 25.6 & $\pm 2.3^{\mathrm{b}}$ \\
\hline RS & 27.2 & $\pm 2.1^{\mathrm{q}}$ & 35.2 & \pm 1.8 \\
\hline RS + Veh & 24.7 & $\pm 3.2^{q}$ & 32.6 & \pm 3.2 \\
\hline $\mathrm{RS}+\mathrm{SERT}$ & 28.6 & \pm 2.3 & 24.9 & $\pm 2.1^{\mathrm{b}}$ \\
\hline
\end{tabular}

Mean values \pm error standard in the different experimental groups ( $N=6-8$ per group). ${ }^{\natural} p<0.01$ and ${ }^{q} p<0.05$ indicate significant differences between males and females after the experimental procedure; bindicates the main effect of SERT in males vs. Control; ${ }^{*} p<0.05$, indicates the significant decrease of the ASR latency as an effect of the intraperitoneal injections with vehicle in males, when compared to baseline. 


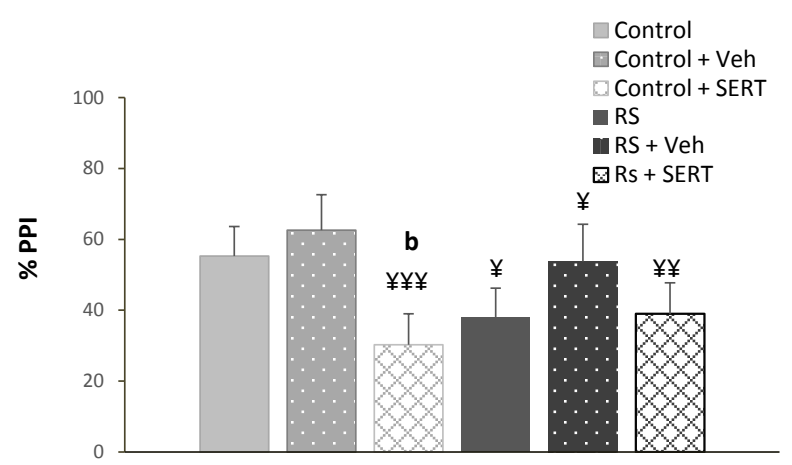

(a)

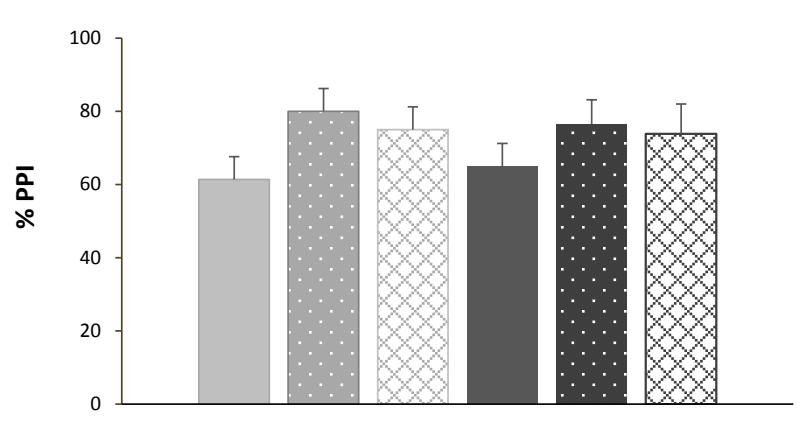

(b)

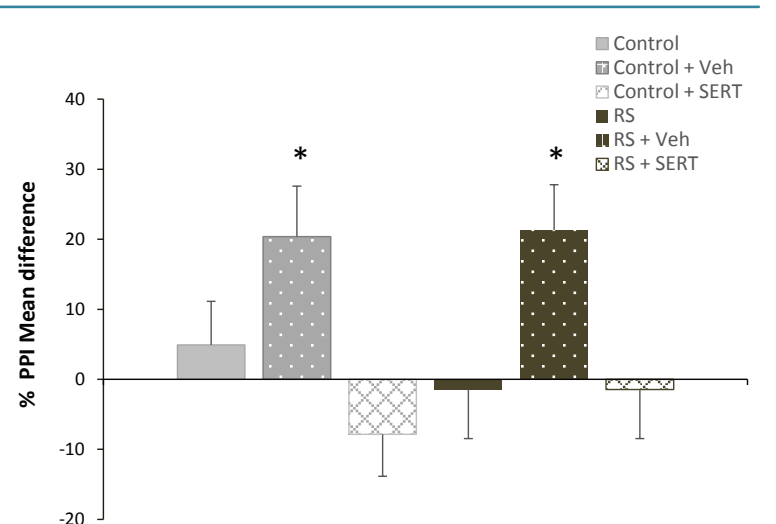

(c)

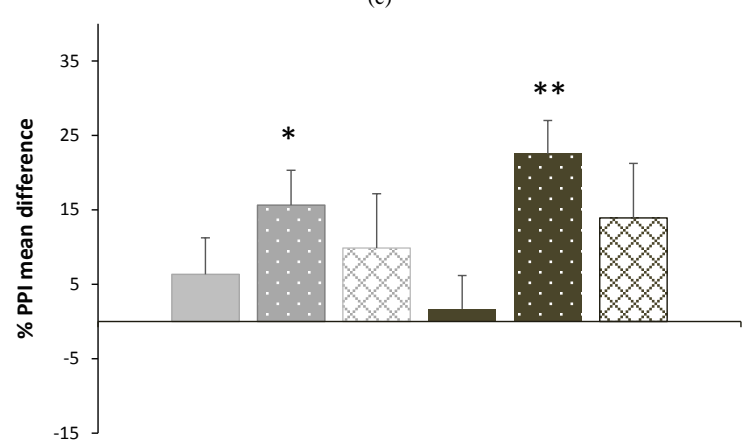

(d)

Figure 7. Percentage of prepulse inhibition (PPI) of experiment 2. Percentage of prepulse inhibition in females (a) and males (b) for the 6 experimental groups: previously stressed/not stressed and not injected (RS; Control); and previously stressed/not stressed and intraperitoneal (i.p.) injected with SERT (5 mg/kg/day) (RS + SERT Control + SERT), or vehicle (RS + Veh; Control + Veh) for 8 days. ${ }^{¥ ¥} p<0.001$, ${ }^{¥ ¥} p<0.01$ and ${ }^{¥} p<0.05$ indicate the significant differences between males and females; ${ }^{b} p<0.05$, indicates the main effect of Sertraline in females. Mean differences \pm S.E. in the PPI values for females (c) and males (d) induced by the experimental paradigms. ${ }^{* *} p<0.01$ and ${ }^{*} p<0.05$, indicate the significant increase of the PPI as effect of the i.p. injections with vehicle in both sexes. (a) Females; (b) Males; (c) Females; (d) Males.

\subsubsection{Variations in Body Weight}

The body weights of all the animals increased along the 18 days of the experiment $\left(\mathrm{F}_{1,39}=406.7, p<0.001\right.$, in females and, $\mathrm{F}_{1,44}=704.01, \mathrm{p}<0.001$ in males). I.p. injections with SERT or saline for 8 days did not induce significant changes in the growth of the animals of either sex $\left(F_{1,39}=0.11\right.$, and $\left.F_{1,40}=2.17\right)$. However, following SERT administration (regardless of stress) in the males from both groups, the drug affected body weight gain slightly (Control + SERT and RS+SERT males respectively lost $7.4 \pm 3.2 \mathrm{~g}$ and $6.3 \pm 2.9 \mathrm{~g}$ in comparison with their controls).

Furthermore, ten days after completion of the restraint stress protocol the body weight gain of previously stressed males was still affected, $\mathrm{F}_{1,44}=4.9, p=0.03$, (stressed males lost $8.5 \pm 3.8 \mathrm{~g}$ when compared to their controls, data not shown).

\subsection{Third Experiment}

Given the large differences found in the behavioral parameters of each sex in response to each type of stressful condition and to SERT treatment, in this experiment our main goal was to extend the results by comparing the effects of each paradigm on later stress responsiveness.

Thus, one day after the last test ended the animals of both sexes subjected to each type of paradigm-restraint stress, i.p. injections with SERT or vehicle, or controls-were exposed to a new stressor, IMO. Blood samples were extracted and compared with those of a group of undisturbed animals (NO-IMO).

\subsubsection{Hematological Analyses}

A main effect of group was found in both sexes for all parameters $(p<0.001)$, except in erythrocytes (Table 3). A significant increase in the amount of hemoglobin (g/dl), hematocrit (\%) and platelet volume (MPV) in the 
Table 3. Hematological data.

\begin{tabular}{|c|c|c|c|c|c|c|c|}
\hline \multicolumn{2}{|c|}{ Experimental groups } & \multirow{2}{*}{$\begin{array}{c}\begin{array}{c}\text { Erythrocytes } \\
(\mathbf{1 0} / \boldsymbol{\mu l})\end{array} \\
7.8 \pm 0.1\end{array}$} & \multirow{2}{*}{$\begin{array}{c}\text { Hemoglobin } \\
\text { (g/dl) }\end{array}$} & \multirow{2}{*}{$\begin{array}{c}\begin{array}{c}\text { Hematocrit } \\
\text { (\%) }\end{array} \\
40.4 \pm 0.7\end{array}$} & \multirow{2}{*}{$\begin{array}{c}\begin{array}{c}\text { MCH } \\
\text { (pg) }\end{array} \\
19.6 \pm 0.2\end{array}$} & \multirow{2}{*}{$\begin{array}{c}\begin{array}{c}\text { Platelet } \\
\left(\mathbf{1 0}^{3} / \boldsymbol{\mu l}\right)\end{array} \\
914.1 .5 \pm 60.4\end{array}$} & \multirow{2}{*}{$\begin{array}{c}\text { MPV fL }\left(\boldsymbol{\mu m}^{\mathbf{3}}\right) \\
7.9 \pm 0.2\end{array}$} \\
\hline \multirow{5}{*}{ Females } & No-IMO & & & & & & \\
\hline & Control & $7.8 \pm 0.3$ & $15.7 \pm 0.3^{Y}$ & $45.4 \pm 1.6^{* * \Psi}$ & $19.9 \pm 0.7$ & $1036.3 \pm 62.8$ & $10.9 \pm 0.3^{* *}$ \\
\hline & Restraint stress & $7.9 \pm 0.3$ & $16.6 \pm 0.4$ & $44.0 \pm 1.6$ & $20.7 \pm 0.4$ & $1411.2 \pm 71.1^{* *_{a}}$ & $11.0 \pm 0.5^{*}$ \\
\hline & Control + Vehicle & $7.4 \pm 0.2^{Y}$ & $13.8 \pm 0.6$ iii & $37.9 \pm 0.9 \mathrm{ii}^{\mathrm{y}}$ & $17.8 \pm 0.6^{* * \text { iii }}$ & $771.6 \pm 88.2$ & $10.1 \pm 0.5^{*}$ \\
\hline & Control + SERT & $7.0 \pm 0.5$ & $15.2 \pm 0.6$ & $39.6 \pm 1.7$ & $20.6 \pm 0.5^{\mathrm{bb}}$ & $866.2 \pm 128.3$ & $10.5 \pm 0.7^{*}$ \\
\hline \multirow{7}{*}{ Males } & & $\mathrm{F}=1.3, \mathrm{~ns}$ & $\begin{array}{l}F=11.3 \\
p<0.001\end{array}$ & $\begin{array}{c}\mathrm{F}=64 \\
p<0.001\end{array}$ & $\begin{array}{l}F=12.9 \\
p<0.001\end{array}$ & $\begin{array}{l}F=10.4 \\
p<0.001\end{array}$ & $\begin{array}{c}\mathrm{F}=5.5 \\
p<0.001\end{array}$ \\
\hline & No-IMO & $8.2 \pm 0.2$ & $15.4 \pm 0.2$ & $40.7 \pm 0.5$ & $18.7 \pm 0.1$ & $908.5 \pm 61.1$ & $7.7 \pm 0.1$ \\
\hline & Control & $8.4 \pm 0.2$ & $17.2 \pm 0.2$ & $47.6 \pm 1.0^{* * * *}$ & $19.7 \pm 0.3$ & $927.3 \pm 62.8$ & $10.8 \pm 0.3^{* *}$ \\
\hline & Restraint stress & $7.7 \pm 0.3$ & $16.2 \pm 0.3$ & $42.1 \pm 1.2$ & $20.9 \pm 0.2^{* *}$ & $1254.8 \pm 67.1^{* *_{a}}$ & $11.4 \pm 0.5^{* *}$ \\
\hline & Control + Vehicle & $8.1 \pm 0.2$ & $14.5 \pm 0.4^{\mathrm{iii}}$ & $43.1 \pm 2.0^{\mathrm{ii}}$ & $17.9 \pm 0.3^{\mathrm{ii}}$ & $707.6 \pm 108.2$ & $9.6 \pm 0.4$ \\
\hline & Control + SERT & $8.1 \pm 0.4$ & $14.6 \pm 0.5^{\mathrm{ii}}$ & $38.5 \pm 1.5^{\mathrm{iii}}$ & $20.4 \pm 0.5^{\mathrm{bb}}$ & $728.2 \pm 124.3$ & $12.3 \pm 0.6^{* * b b}$ \\
\hline & & $\mathrm{F}=1.9, \mathrm{~ns}$ & $\begin{array}{c}F=9.3 \\
p<0.001\end{array}$ & $\begin{array}{l}F=11.7 \\
p<0.001\end{array}$ & $\begin{array}{c}F=9.5 \\
p<0.001\end{array}$ & $\begin{array}{c}F=8.5 \\
p<0.001\end{array}$ & $\begin{array}{l}F=10.5 \\
p<0.001\end{array}$ \\
\hline
\end{tabular}

Plasma values obtained in the arterial blood in the animals of both sexes 10 minutes after exposure to IMO stress (Restraint stress, Control + Vehicle, Control + SERT) or not exposed to IMO (No-IMO). Mean values \pm S.E. in the different experimental groups $(\mathrm{N}=6$ per group and sex). Abbreviations: MCH, mean corpuscular hemoglobin concentrations; MPV, mean platelet volume. ${ }^{\sharp} p<0.05$ indicates significant differences between males and females; ${ }^{* * *} p<0.001,{ }^{* *} p<0.01$ and ${ }^{*} p<0.05$, indicate a significant difference when compared to No-IMO; a $p<0.05$, indicates the main effect of restraint stress (different from Controls); ${ }^{\text {bb }} p<0.01$ indicates a main effect of SERT (different from vehicle); iii $\mathrm{p}<0.001$, ${ }^{\text {ii }} p<0.01$ and ${ }^{\mathrm{i}} p<0.05$, indicate a main effect of the intraperitoneal procedure (different from controls).

animals subjected to acute stress (IMO) was found as compared to undisturbed control animals (No-IMO).

As shown in Table 3, differences were found according to the type of the previous stressful paradigm. Whereas the previously restrained animals responded intensely when exposed to the new stressor, in the animals subjected to daily injections the concentration of hemoglobin, hematocrit, $\mathrm{MCH}$, and platelet values did not increase. This suggests that in these animals the stress response is disturbed, an effect that was not fully reversed by SERT treatment. Moreover, no differences in the hematological values according to sex were found in undisturbed animals. However, differences were found in both the animals subjected to IMO and in the animals previously subjected to a repeated i.p. procedure, the males exhibiting higher values of erythrocytes, hemoglobin and hematocrit in blood plasma.

\subsubsection{Metabolic Analyses}

As shown in Table 4, the acute stress condition (IMO) increased the release of almost all metabolic parameters studied in blood serum in both sexes. Even so, albumin and bilirubin and the cytosolic enzymes LDH and GOT were significantly increased in the previously stressed animals (whether with restraint or i.p. vehicle) in comparison with the undisturbed animals (Table 4); SERT-treatment partly counteracted this effect. No sex differences were seen in the parameters studied, but in males in particular, restraint stress proved to exacerbate the effects of the IMO stress.

\subsubsection{Leukogram Analysis}

As shown in Table 5, the acute condition of IMO stress did not affect the leukocyte profile in Controls. Differently, in animals that underwent a prior stressor, leukopenia was observed in both sexes. This condition was more prominent in the animals subjected to the daily injection procedure, an effect that was not reversed by SERT. In both sexes the total number of leukocytes, of neutrophils, lymphocytes and monocytes were significantly lower in vehicle-injected animals than Controls (Table 5). In the other leukocyte cells analyzed (basophil's and eosinophil's granulocytes) no differences were found as effect of the treatments animals experienced. Moreover no sex-dependent differences were found in none parameter measured, but again restraint proved to affect more the males than the females. 
Table 4. Biochemical serum values.

\begin{tabular}{|c|c|c|c|c|c|c|c|}
\hline \multicolumn{2}{|c|}{ Experimental groups } & $\begin{array}{l}\text { T-pro } \\
\text { (g/dl) }\end{array}$ & $\begin{array}{c}\text { Alb } \\
\text { (g/dl) }\end{array}$ & $\begin{array}{c}\text { T-bil } \\
\text { (mg/dl) }\end{array}$ & $\begin{array}{l}\text { GOT } \\
\text { (IU/I) }\end{array}$ & $\begin{array}{c}\text { GPT } \\
\text { (IU/l) }\end{array}$ & $\begin{array}{l}\text { LDH } \\
\text { (IU/l) }\end{array}$ \\
\hline \multirow{6}{*}{ Females } & No-IMO & $6.0 \pm 0.2$ & $3.3 \pm 0.1$ & $0.30 \pm 0.1$ & $54.6 \pm 8.7$ & $27.7 \pm 5.8$ & $423.4 \pm 122$ \\
\hline & Control & $6.2 \pm 0.1$ & $3.5 \pm 0.1$ & $0.60 \pm 0.1$ & $107.9 \pm 8.2^{* *}$ & $37.5 \pm 6.8$ & $2589.2 \pm 350^{* * *}$ \\
\hline & Restraint stress & $6.7 \pm 0.1$ & $3.8 \pm 0.1^{* *}$ & $0.55 \pm 0.1$ & $129.4 \pm 8.1^{* * *}$ & $29.2 \pm 4.7$ & $3579.7 \pm 247^{* * * a}$ \\
\hline & Control + Vehicle & $6.1 \pm 0.2$ & $3.8 \pm 0.1^{* *}$ & $0.43 \pm 0.1$ & $117.8 \pm 6.8^{* * *}$ & $22.9 \pm 4.3$ & $3324.2 \pm 230^{* * *}$ \\
\hline & Control + SERT & $5.3 \pm 0.2$ & $3.2 \pm 0.1^{\mathrm{bb}}$ & $0.42 \pm 0.1$ & $122.4 \pm 8.1^{* *}$ & $18.4 \pm 4.8$ & $1694.8 \pm 271^{b}$ \\
\hline & & $\begin{array}{c}F=6.1, \\
p=0.001\end{array}$ & $\begin{array}{c}F=8.4 \\
p<0.001\end{array}$ & $\begin{array}{c}\mathrm{F}=1.7 \\
p=\mathrm{ns}\end{array}$ & $\begin{array}{l}F=18.4 \\
p<0.001\end{array}$ & $\mathrm{~F}=2.9, \mathrm{~ns}$ & $\begin{array}{l}F=18.8 \\
p<0.001\end{array}$ \\
\hline \multirow{6}{*}{ Males } & No-IMO & $6.2 \pm 0.2$ & $3.4 \pm 0.1$ & $0.30 \pm 0.1$ & $68.2 \pm 9.1$ & 29.7. \pm 5.8 & $485.7 \pm 242$ \\
\hline & Control & $6.2 \pm 0.1$ & $3.4 \pm 0.1$ & $0.36 \pm 0.0$ & $101.8 \pm 8.5$ & $34.7 \pm 4.2$ & $1614.9 \pm 263^{* ¥}$ \\
\hline & Restraint stress & $6.6 \pm 0.2$ & $3.8 \pm 0.1^{\mathrm{a}}$ & $0.70 \pm 0.1^{* a}$ & $136.5 \pm 7.1^{* * * a}$ & $31.2 \pm 5.7$ & $3081.7 \pm 237^{* * * a}$ \\
\hline & Control + Vehicle & $6.2 \pm 0.2$ & $3.7 \pm 0.1$ & $0.37 \pm 0.1$ & $109.5 \pm 7.5^{*}$ & $37.2 \pm 6.0^{¥}$ & $3314.2 \pm 260^{* * * i i}$ \\
\hline & Control + SERT & $5.5 \pm 0.1$ & $3.4 \pm 0.0$ & $0.28 \pm 0.1$ & $106.4 \pm 8.0$ & $18.5 \pm 4.8^{b}$ & $1564.8 \pm 272^{\mathrm{bb}}$ \\
\hline & & $\begin{array}{l}\mathrm{F}=3.2 \\
p=0.02\end{array}$ & $\begin{array}{l}F=3.4 \\
p=0.02\end{array}$ & $\begin{array}{c}F=4.7 \\
p=0.003\end{array}$ & $\begin{array}{c}F=8.2 \\
p<0.001\end{array}$ & $\begin{array}{c}F=4.2 \\
p=0.006\end{array}$ & $\begin{array}{l}F=12.5 \\
p<0.001\end{array}$ \\
\hline
\end{tabular}

Mean values \pm S.E. in the different experimental groups $(\mathrm{N}=6$ per group and sex). Abbreviations: T-Pro, total protein; Alb, albumin; T-Bil, total bilirubin; GOT, glutamic oxalacetic transaminase; GPT, glutamic pyruvic transaminase; LDH, lactate dehydrogenase. ${ }^{* * *} p<0.001,{ }^{* * *} p<0.01$ and ${ }^{*} p<$ 0.05 , indicate a significant difference when compared to No-IMO; a $p<0.05$, indicates the main effect of restraint stress (different from Controls); ${ }^{b} p<$ 0.01 and ${ }^{\mathrm{b}} p<0.05$ indicates the main effect of SERT (different from Control+ Vehicle); ${ }^{\text {ii }} p<0.01$ indicates a main effect of the intraperitoneal procedure (different from controls); ${ }^{\sharp} p<0.05$ indicates significant differences between males and females.

Table 5. Leukogram.

\begin{tabular}{|c|c|c|c|c|c|}
\hline \multicolumn{2}{|c|}{ Experimental groups } & \multirow{2}{*}{$\begin{array}{c}\begin{array}{c}\text { Leukocytes } \\
\left(\mathbf{( 1 0}^{3} / \mathbf{\mu l}\right)\end{array} \\
4.8 \pm 0.4\end{array}$} & \multirow{2}{*}{$\begin{array}{c}\begin{array}{c}\text { Neutrophils } \\
\left(\mathbf{1 0}^{\mathbf{3}} / \mathbf{\mu l}\right)\end{array} \\
0.9 \pm 0.1\end{array}$} & \multirow{2}{*}{$\begin{array}{c}\begin{array}{c}\text { Lymphocytes } \\
\left(\mathbf{1 0}^{3} / \boldsymbol{\mu l}\right)\end{array} \\
3.5 \pm 0.4\end{array}$} & \multirow{2}{*}{$\begin{array}{c}\begin{array}{c}\text { Monocytes } \\
\left(\mathbf{1 0}^{3} / \mathbf{\mu l}\right)\end{array} \\
0.08 \pm 0.01\end{array}$} \\
\hline \multirow{5}{*}{ Females } & No-IMO & & & & \\
\hline & Control & $5.2 \pm 0.4$ & $0.8 \pm 0.1$ & $4.0 \pm 0.3$ & $0.07 \pm 0.01$ \\
\hline & Restraint stress & $3.2 \pm 0.7$ & $0.4 \pm 0.1$ & $2.7 \pm 0.5 \mathrm{i}$ & $0.04 \pm 0.01$ \\
\hline & Control + Vehicle & $1.5 \pm 0.4^{* * * i i i}$ & $0.4 \pm 0.4^{* * i i}$ & $0.9 \pm 0.7^{* *_{\mathrm{iii}}}$ & $0.03 \pm 0.01^{* \mathrm{ii}}$ \\
\hline & Control + SERT & $1.1 \pm 0.7^{* * i i i}$ & $0.4 \pm 0.3^{*_{\mathrm{i}}}$ & $0.5 \pm 0.5^{* * \mathrm{iii}}$ & $0.05 \pm 0.01^{*}$ \\
\hline \multirow{7}{*}{ Males } & & $F=13.2, p<0.001$ & $F=7.2, p<0.001$ & $F=11.5 p<0.001$ & $F=5.6, p=0.001$ \\
\hline & No-IMO & $5.9 \pm 0.5$ & $0.9 \pm 0.1$ & $3.9 \pm 0.2$ & $0.09 \pm 0.01$ \\
\hline & Control & $5.8 \pm 0.5$ & $0.9 \pm 0.1$ & $4.7 \pm 0.3$ & $0.10 \pm 0.01$ \\
\hline & Restraint stress & $3.5 \pm 0.6^{*} \mathrm{a}$ & $0.6 \pm 0.1$ & $2.7 \pm 0.4$ & $0.03 \pm 0.01^{* \mathrm{aa}}$ \\
\hline & Control + Vehicle & $2.6 \pm 0.5^{* * i i i}$ & $0.7 \pm 0.1$ & $1.8 \pm 0.8^{* \mathrm{iii}}$ & $0.05 \pm 0.01^{\mathrm{i}}$ \\
\hline & Control + SERT & $1.7 \pm 0.6^{* * * i i i}$ & $0.4 \pm 0.1$ & $0.6 \pm 0.6^{* * \mathrm{iii}}$ & $0.06 \pm 0.01^{* \mathrm{ii}}$ \\
\hline & & $F=11.3, p<0.001$ & $\mathrm{~F}=2.9, p=0.031$ & $\mathrm{~F}=9.4, p<0.001$ & $F=7.6, p<0.001$ \\
\hline
\end{tabular}

Plasma values obtained in the arterial blood in female and male animals 10 minutes after exposure to IMO stress. Mean values \pm S.E. in the different experimental groups ( $\mathrm{N}=6$ per group). ${ }^{* * *} p<0.001,{ }^{* *} p<0.01$ and ${ }^{*} p<0.05$, indicate a significant difference when compared to No-IMO; ${ }^{\text {a }} p<0.01$, a $p<0.05$, indicates the main effect of restraint stress (different from IMO); ${ }^{\text {iii }} p<0.001$, ii $\mathrm{p}<0.01$ and ${ }^{\mathrm{i}} p<0.05$, indicate a main effect of the intraperitoneal procedure (different from IMO). 


\section{Discussion}

In agreement with previous authors, the first experiment vouches that 7 days of restraint stress was enough to induce changes in later behavior and physiological blood parameters [25] [28] [43]. Our data indicate that sex was a main factor in this stress-type sensitivity, males being more affected by restraining than females.

Repeated injections of vehicle were sufficient to affect sensorimotor gating, and hematological and metabolic parameters in both sexes. Using the commonly prescribed antidepressant SERT, we were able to prevent almost all the deleterious effects of the stressful procedures. However, again a different sensitivity to SERT treatment was found in each sex, the drug being more effective in stabilizing the behavioral parameters in females, which partly corroborates the clinical findings regarding gender differences in the antidepressant treatment with such drug, in human beings [46]. Furthermore, SERT administration i.p. for 8 days was unable to normalize the deregulation of the immune system induced by stress. Thus, our data extend previous findings concerning the effects of stress and the antidepressant response, by evaluating male and female rats at the same time that confirmed the differences across the sexes.

\subsection{Body Weight Changes with Stress}

Our data show that one-week of restraint stress was sufficient to affect growth in young rats, an effect that was more marked in males. It is assumed that the decrease in body weight is a good physiological marker of stress, and hence the intensity and duration of the stressor would be determining factors in the results. With more intense stressors, such as IMO for 14 days [53] or 8 hours restriction/day plus the use of a variable stress paradigm [3], more spectacular results have been achieved. However, in the present work we failed to detect significant differences in weight gain in the restrained animals subjected later to the i.p. procedure or in those treated with SERT.

\subsection{The Effects of Stress on Startle and PPI Modulation}

It is well known that the startle response is very sensitive to stress and anxiety both in humans and animals [11] [23] [52] [54]. In the present work, our results indicated there were no differences in ASR amplitude means in either sex as a function of stress paradigm or SERT treatment. However, we found that long-term habituation was disrupted as an effect of RS, in males.

In control animals of both sexes, startle amplitude decreased slightly each time it was examined (data not shown), indicating that a kind of habituation had occurred [11]. Previous works have confirmed the existence of acoustic startle habituation both between consecutive trials during a single session [11] [23] [36] [50] and between the ASR sessions [13] [55]. Nevertheless, ten days after the end of the restraint stress procedure, the RS males exhibited an increase in startle amplitude (when compared to the baseline). These results are partly in agreement with what has been reported in humans with psychopathological symptoms [19] [23]. These authors reported that their patients did not become habituated easily during the startle probe, increasing startle or maintaining it at the same levels in each exposure to the test.

When we analyzed PPI we observed a significant increase in PPI up to an age of 12 weeks in the animals of both sexes regardless of treatment, as we previously found in our laboratory, in males (unpublished data). At that moment, in the control animals PPI remained stable among sessions, as expected [36] [55]. According to the literature, stress affects PPI. PPI may be enhanced by fear or in response to emotional conditions [14] [55] [56]. Our data show that, alone, one week of restraint stress was not sufficient to induce changes in PPI. Also, a single i.p. injection with vehicle had no effects on either the startle reflex or PPI. However, when the animals were exposed to repeated injections with saline, a significant increase in PPI was observed in both sexes, an effect that was counteracted by SERT, although more efficiently in females. The PPI enhancement after daily injections could be interpreted in the sense that this injection procedure might have facilitated attention and vigilance after the animals had been exposed to an adverse condition [14] [55] [57]. In fact, other authors have reported that epeated injections [58], or even blood sampling [52] [59], are sufficient to increase corticosterone (CORT) levels (an indicator of stress response) and to increase the startle reflex (in the first presentation trials) [58] and PPI in rodents [52]. However, although it has been reported that changes in the environment are sufficient to enhance PPI in both humans and rodents [18] [55] [57] [60]_in humans PPI may even be increased if the prepulse stimulus has an affective component [60] — the route through which the drugs are supplied is not normally taken into account and its aversion value is not considered [13] [35] [37] [58]. 
Furthermore, the importance of taking the time to respond to the startle stimulus as an adaptive ability has recently been reported [61]. This is meaningful, considering the protective function of the startle reflex; when animals are first challenged by unexpected loud noises, a faster startle response is expected because the environment is potentially unsecure. Then, after repeated and inconsequential encounters with the same stimulus sequences, the startle should slow down, due to habituation. With repeated exposure to the test sessions (from ASR1 to ASR4) we found that whereas restraint stress did not affect ASR or PPI latency in either sex, the procedure of repeatedly injecting the rats induced a significant decrease in latencies. These animals speeded up their startle response, in contrast to habituation. This suggests that they became more reactive and fearful [61], an effect that SERT-pretreatment totally reversed in females but not in males.

\subsection{The Sensitivity to Stress Is Sex-Dependent}

In comparison with the amount of work conducted on the effects of stress and their modulation in startle and sensorimotor gating mechanisms in males, the respective literature addressing female responses is fairly limited. Here, we found that sex was a major factor affecting the results.

At the beginning of the experiment, the males exhibited higher startle amplitudes and PPI levels than the females, in agreement with the previous data [18]. In contrast to other authors [62] [63], Lehmann's group described the existence of consistent differences between male and female Wistar rats in sensorimotor gating mechanisms [18]. It is now well established that these differences also exist in humans [36] [64].

The fact that males reach higher startle amplitudes than females is evident, since in rats the ASR is measured based on acceleration [18]. With regard to PPI, this physical law does not apply since the PPI is calculated as a percentage of reduction in ASR and not as an absolute value. Accordingly, body weight is not a determining factor. In fact, our data show that when the animals reached adulthood (at 12 weeks of age) the differences in startle habituation and PPI values between the sexes were no longer found between controls, but were found among the animals that experienced stressful paradigms. Apparently, females were somewhat more sensitive to the injection procedure and males were more sensitive to restraint. To the best of our knowledge, the differences in our data concerning startle and PPI modulation due to the type of the stressor in each sex have never been considered. Previously, some studies reported different results with physical vs. emotional stressors [14] [56]; however, most of those studies were conducted in males.

The reported sex-differences could be due to changes in reproductive hormones, in particular estrogen (E2) [4] [62]. Nevertheless, when the differences at E2 levels throughout the estrous cycle were considered in females [49], neither PPI nor the startle values were changed, as we did not find any correlation between E2 levels and PPI, or between E2 levels and startle at any time point. Moreover, recently, it has been reported [48] [65], the estrous cycle had no effects on ASR amplitude and PPI when tested in random phases of the estrous cycle.

When we examined the physiological analyses, whereas no sex differences were found in the biochemical parameters or leukogram, some differences between the males and females were found in the haemostatic response to stress. In agreement with our results whereas under basal conditions, no differences between the sexes in chemical or hematological parameters are expected [66], several authors have reported differences in the stress response [42] [67]-[69].

\subsection{SERT Administration Counteracts the Effects of Stress on Startle and PPI}

According to the literature, the startle reflex and its modulations are sensitive to 5-HT levels and to the administration of SSRIs, such as SERT [34] [35] [37]. In the present study, SERT did not act in control animals; but in the animals exposed to stressful conditions SERT counteracted the effects of stress, although more efficiently in females. Results were only seen after 8 days of SERT administration; a single administration of SERT did not change any of the behavioral measures. This agrees with previous works, in the sense that antidepressants (such as SSRIs) may normalize or stabilize serotonin function and restore stress-induced behavioral changes [1]. Only repeated treatment with SSRIs affords the desired effects by blocking the harmful effects of stress [29] [30] [54] [70] [71] and no effects have been reported with acute treatment [35]. Nevertheless, in our study, the effects of SERT in modulating startle and PPI were different according to sex; SERT treatment was slightly more effective in female rats than in males. In fact, sex differences in 5-HT levels have been reported in many structures of the corticolimbic region known to regulate stress and emotion processing [72] [73]. Moreover, the spontaneous firing rate of dorsal raphe neurons (DRN) in males is more than $40 \%$ higher than in females [73]. Considering 
these sex differences, it could be suggested that the already increased DRN 5-HT activity in males could be related to the observed differences of SERT in reversing anxiety-related behaviors [74]. The serotonergic signaling can either facilitate or attenuate anxious states, depending on the site of action and the specific serotonin receptor subtype involved [37]. However, the present study, using the same administration route and treatment duration, highlights the differences between the sexes in the antidepressant response, with regard to anti-anxiety effects, i.e. modulating the startle reflex and PPI in response to stressors.

\subsection{Changes in Physiological Parameters with Stress}

We found that physiological parameters, together with our behavioral observations, were useful for monitoring the stress responsiveness and the role of SERT protecting it. After the animals had been exposed to IMO stress, changes in the hematological and metabolic values were found in all the experimental groups in comparison with the undisturbed controls.

When animals are exposed to an acute stressor physiological changes in the animals' body are expected in response to the strong increase in glucocorticoids (GCs) and catecholamines secreted by the adrenal glands [1]. Blood coagulation accelerates, eliciting hemoconcentration [2]; the catabolic characteristics of GCs produces a rapid mobilization of amino acids and lipids [4] [75] and the immune response is faster, enhanced by catecholamines (increasing pro-inflammatory cytokine production) but soon suppressed if GCs remain at high levels [1] [5] [7] [76]. Together, these conditions have evident advantages for the animal's short-term survival, which are of utmost importance when it must face a potential danger [7] [12]. Thus, and in agreement with previous studies, after being exposed to acute stress the young rats in our study exhibited a significant increase in hematocrit, hemoglobin and platelet numbers [2] [12] [77]. Surprisingly, in the animals previously exposed to daily injections, the stress-response was less evident.

Although there are contradictory results in humans in regard to physiological habituation to stress [12] [78], in agreement with our data, it has been reported that subjects displaying negative affect showed consistently reduced coagulation activation in response to acute psychosocial stress [79], and that this was the exact opposite of what they expected in their first hypothesis. Also, in rodents, it was reported that rats exposed to an early type of stress (social deprivation) exhibited failure in fear potentiation [14] and, specifically, the same authors stated that previously injected rats exhibited signs of learned helplessness. As those rats had lost, somewhat, the ability to attend to ecologically important sensory signals. Moreover, when animals are subjected to inescapable stress conditions, the ascendant activity of the serotonergic system may become deregulated [80], the involvement of the serotoninergic system in regulating the autonomous functions having been suggested [40] [41]. The present study shows that SERT administration attenuates the changes induced by the i.p., affecting the hemostatic response to stress.

Moreover, our data also point to a significant increase in cytoplasmic enzymes, (GOT), and lactate dehydrogenase (LDH) in response to IMO stress in the animals of both sexes, as expected [75]. Even so, it almost doubled the intensity in previously stressed animals as compared to controls, indicating potential tissue-damage in previously stressed animals [81]. Rats exposed to either restraint stress or vehicle injections plus IMO had twice the absolute values of LDH and GOT enzymes in comparison with animals only subjected to IMO. Importantly, SERT administration prevented the prior stress-induced increase in enzyme levels, showing that the drug plays an important role in the preservation of cellular integrity. Nevertheless, recent reports have associated the use of SERT with acute liver failure [82] [83]. Despite intensive investigation using SERT in both animals and humans, the hepatotoxicity of Sertraline remains to be fully elucidated. The toxicity of higher doses, collateral factors, and the method used to study it (in vitro) are major factors that can affect the effects of SERT [83]. Moreover when the impact of SERT on post-myocardial infarction was studied [84] [85], it was observed that besides being safe, this antidepressant drug was efficacious in patients with unstable ischemic heart disease, decreasing the incidence of severe adverse cardiovascular events [85].

\subsection{The Effects of Stress and SERT on Immune Function}

In the present study, stress induced a dramatic decrease in the total number of leukocytes in rats of both sexes. The significant decrease in the number of leukocytes and lymphocytes after stress exposure has already been reported in several species [86] [87] and should be followed by a slow and complete recovery once it ends [76]. In fact, we found no changes in the animals exposed to IMO when compared to the undisturbed animals (after 
the recovery period had ended). By contrast, the animals that were exposed to stressful conditions prior to IMO exhibited a persistent fall in the leukocyte count. Even at 10 days after the stress had ended, the animals exhibited a decrease in the total WBC concentration. This prolonged effect is consistent with recent findings reported from our laboratory, where differences were found in prenatally stressed offspring when they were studied in adulthood [50]. We also reported that by administering SERT for two months during adolescence it was possible to reverse the deleterious effects of prenatal stress on the leukocyte count. In the present study, pretreatment with SERT i.p. for 8 days was not sufficient to normalize stress-induced immunosuppression. The inhibition of the reuptake and synthesis of 5-HT does not occur in an immediate way [29] [71] [88] [89]. One week of administration of the drug is sufficient to maintain plasma drug levels steady [90], but normally the antidepressant effects can only be reached after a few weeks of treatment [46]. It could be surmised that this period of SERT treatment would be sufficient to lead to an increase in the basal levels of 5-HT in the brain [71] [88] [91], but insufficient to induce the adaptive changes in monoaminergic neurotransmission or in neurotrophic factors, and as consequence, unable to modulate the immune reactivity and possibly the central actions of the cytokines [9].

\section{Conclusion}

The main results of our study suggest there are sex-dependent differences both in the behavioral modulation (in startle, PPI and the latencies of both) and in the physiological response to a new stressor depending on the type of the previous stress condition (restraint vs. daily injections). Moreover, we tested the hypothesis that by administrating SERT, a well-known modulator of the neuronal circuitry involved in anxiety regulation, we could modulate the stress-elicited effects in young rats of both sexes. In fact, SERT has been shown to be able to modulate the startle and the PPI both in vehicle-injected and restrained animals, although more efficiently in females than males. The present study also shows that previous treatment with SERT attenuates some of the biochemical and hematological parameter changes induced by stress; however, SERT administration for 8 days does not reverse the deleterious effects of stress on the immune profile.

\section{Acknowledgements}

This work was supported by the University of Salamanca Research Support Grant 2015 to Dr. Dolores E. López.

\section{References}

[1] McEwen, B.S. (2008) Central Effects of Stress Hormones in Health and Disease: Understanding the Protective and Damaging Effects of Stress and Stress Mediators. European Journal of Pharmacology, 583, 174-185. http://dx.doi.org/10.1016/j.ejphar.2007.11.071

[2] von Kanel, R., Kudielka, B.M., Haeberli, A., Stutz M., Fischer, J.E. and Patterson, S.M. (2009) Prothrombotic Changes with Acute Psychological Stress: Combined Effect of Hemoconcentration and Genuine Coagulation Activation. Thrombosis Research, 123, 622-630. http://dx.doi.org/10.1016/j.thromres.2008.05.014

[3] Cox, B.M., Alsawah, F., McNeill, P.C., Galloway, M.P. and Perrine, S.A. (2011) Neurochemical, Hormonal, and Behavioral Effects of Chronic Unpredictable Stress in the Rat. Behavioural Brain Research, 220, 106-111. http://dx.doi.org/10.1016/j.bbr.2011.01.038

[4] Swaab, D.F., Bao, A.-M. and Lucassen, P.J. (2005) The Stress System in the Human Brain in Depression and Neurodegeneration. Ageing Research Reviews, 4, 141-194. http://dx.doi.org/10.1016/j.arr.2005.03.003

[5] Black, P.H. and Garbutt, D. (2002) Stress, Inflammation and Cardiovascular Disease. Journal of Psychosomatic Research, 52, 1-23. http://dx.doi.org/10.1016/S0022-3999(01)00302-6

[6] Bai, Y.-M., Su, T.-P., Chen, M.-H., Chen, T.-J. and Chang, W.-H. (2013) Risk of Developing Diabetes Mellitus and Hyperlipidemia among Patients with Bipolar Disorder, Major Depressive Disorder, and Schizophrenia: A 10-Year Nationwide Population-Based Prospective Cohort Study. Journal of Affective Disorders, 150, 57-62. http://dx.doi.org/10.1016/j.jad.2013.02.019

[7] Bierhaus, A., Humpert, P.M. and Nawroth, P.P. (2006) Linking Stress to Inflammation. Anesthesiology Clinics of North America, 24, 325-340. http://dx.doi.org/10.1016/j.atc.2006.01.001

[8] de Kloet, E.R., Joels, M. and Holsboer, F. (2005) Stress and the Brain: From Adaptation to Disease. Nature Reviews Neuroscience, 6, 463-475. http://dx.doi.org/10.1038/nrn1683

[9] Leonard, B.E. (2005) The HPA and Immune Axes in Stress: The Involvement of the Serotonergic System. European 
Psychiatry, 20, S302-S306. http://dx.doi.org/10.1016/s0924-9338(05)80180-4

[10] Grissom, N. and Bhatnagar, S. (2009) Habituation to Repeated Stress: Get Used to It. Neurobiology of Learning and Memory, 92, 215-224. http://dx.doi.org/10.1016/j.nlm.2008.07.001

[11] Pilz, P.K.D. and Schnitzler, H.-U. (1996) Habituation and Sensitization of the Acoustic Startle Response in Rats: Amplitude, Threshold, and Latency Measures. Neurobiology of Learning and Memory, 66, 67-79. http://dx.doi.org/10.1006/nlme.1996.0044

[12] Hamer, M., Gibson, E.L., Vuononvirta, R., Williams, E. and Steptoe, A. (2006) Inflammatory and Hemostatic Responses to Repeated Mental Stress: Individual Stability and Habituation over Time. Brain, Behavior, and Immunity, 20, 456-459. http://dx.doi.org/10.1016/j.bbi.2006.01.001

[13] Young, B.J., Helmstetter, F.J., Rabchenuk, S.A. and Leaton, R.N. (1991) Effects of Systemic and Intra-Amygdaloid Diazepam on Long-Term Habituation of Acoustic Startle in Rats. Pharmacology Biochemistry and Behavior, 39, 903909. http://dx.doi.org/10.1016/0091-3057(91)90051-3

[14] Li, N., Ping, J., Wu, R., Wang, C., Wu, X. and Li, L. (2008) Auditory Fear Conditioning Modulates Prepulse Inhibition in Socially Reared Rats and Isolation-Reared Rats. Behavioral Neuroscience, 122, 107-118. http://dx.doi.org/10.1037/0735-7044.122.1.107

[15] Johansson, C., Jackson, D.M., Zhang, J. and Svensson, L. (1995) Prepulse Inhibition of Acoustic Startle, a Measure of Sensorimotor Gating: Effects of Antipsychotics and Other Agents in Rats. Pharmacology Biochemistry and Behavior, 52, 649-654. http://dx.doi.org/10.1016/0091-3057(95)00160-X

[16] Van den Buuse, M. (2007) Pre-Pulse Inhibition. Encyclopedia of Stress. New York, Academic Press, 180-183.

[17] Braff, D.L., Geyer, M.A. and Swerdlow, N.R. (2001) Human Studies of Prepulse Inhibition of Startle: Normal Subjects, Patient Groups, and Pharmacological Studies. Psychopharmacology, 156, 234-258. http://dx.doi.org/10.1007/s002130100810

[18] Lehmann, J., Pryce, C.R. and Feldon, J. (1999) Sex Differences in the Acoustic Startle Response and Prepulse Inhibition in Wistar Rats. Behavioural Brain Research, 104, 113-117. http://dx.doi.org/10.1016/S0166-4328(99)00058-3

[19] Grillon, C. (2002) Startle Reactivity and Anxiety Disorders: Aversive Conditioning, Context, and Neurobiology. Biological Psychiatry, 52, 958-975. http://dx.doi.org/10.1016/S0006-3223(02)01665-7

[20] Geyer, M.A. (2006) The Family of Sensorimotor Gating Disorders: Comorbidities or Diagnostic Overlaps? Neurotoxicity Research, 10, 211-220. http://dx.doi.org/10.1007/BF03033358

[21] Ludewig, S., Ludewig, K., Geyer, M., Hell, D. and Vollenweider, F.X. (2001) Deficient Prepulse Inhibition of the Acoustic Startle Reflex in Panic Disorder. European Neuropsychopharmacology, 11, S312. http://dx.doi.org/10.1016/s0924-977x(01)80434-x

[22] Hoenig, K., Hochrein, A., Quednow, B.B., Maier, W. and Wagner, M. (2005) Impaired Prepulse Inhibition of Acoustic Startle in Obsessive-Compulsive Disorder. Biological Psychiatry, 57, 1153-1158. http://dx.doi.org/10.1016/j.biopsych.2005.01.040

[23] Meincke, U., Light, G.A., Geyer, M.A., Braff, D.L. and Gouzoulis-Mayfrank, E. (2004) Sensitization and Habituation of the Acoustic Startle Reflex in Patients with Schizophrenia. Psychiatry Research, 126, 51-61. http://dx.doi.org/10.1016/j.psychres.2004.01.003

[24] Chen, Y., Mao, Y., Zhou, D., Hu, X., Wang, J. and Ma, Y. (2010) Environmental Enrichment and Chronic Restraint Stress in ICR Mice: Effects on Prepulse Inhibition of Startle and Y-Maze Spatial Recognition Memory. Behavioural Brain Research, 212, 49-55. http://dx.doi.org/10.1016/j.bbr.2010.03.033

[25] Albonetti, M.E. and Farabollini, F. (1993) Effects of Single and Repeated Restraint on the Social Behavior of Male Rats. Physiology \& Behavior, 53, 937-942. http://dx.doi.org/10.1016/0031-9384(93)90272-H

[26] Vermetten, E. and Bremner, J.D. (2002) Circuits and Systems in Stress. I. Preclinical Studies. Depress Anxiety, 15, 126-147. http://dx.doi.org/10.1002/da.10016

[27] Buynitsky, T. and Mostofsky, D.I. (2009) Restraint Stress in Biobehavioral Research: Recent Developments. Neuroscience Biobehavioral Reviews, 33, 1089-1098. http://dx.doi.org/10.1016/j.neubiorev.2009.05.004

[28] Bowman, R.E., Micik, R., Gautreaux, C., Fernandez, L. and Luine, V.N. (2009) Sex-Dependent Changes in Anxiety, Memory, and Monoamines Following One Week of Stress. Physiology \& Behavior, 97, 21-29. http://dx.doi.org/10.1016/j.physbeh.2009.01.012

[29] Giardino, L., Bettelli, C., Pozza, M. and Calzà, L. (1999) Regulation of CCK mRNA Expression in the Rat Brain by Stress and Treatment with Sertraline, a Selective Serotonin Re-Uptake Inhibitor. Brain Research, 824, 304-307. http://dx.doi.org/10.1016/S0006-8993(99)01242-1

[30] Ulloa, J.L., Castañeda, P., Berríos, C., Díaz-Veliz, G., Mora, S., Bravo, J.A., et al. (2010) Comparison of the Antidepressant Sertraline on Differential Depression-Like Behaviors Elicited by Restraint Stress and Repeated Corticosterone 
Administration. Pharmacology Biochemistry and Behavior, 97, 213-221. http://dx.doi.org/10.1016/j.pbb.2010.08.001

[31] Azmitia, E.C. (2001) Modern Views on an Ancient Chemical: Serotonin Effect on Cell Proliferation, Maturation, and Apoptosis. Brain Research Bulletin, 56, 413-424. http://dx.doi.org/10.1016/S0361-9230(01)00614-1

[32] Lauder, J.M. (1990) Ontogeny of the Serotonergic System in the Rat: Serotonin as a Developmental Signal. Annals of the New York Academy of Sciences, 600, 297-313. http://dx.doi.org/10.1111/j.1749-6632.1990.tb16891.X

[33] Quednow, B.B., Kuhn K.-U., Mössner, R., Schwab, S.G., Schuhmacher, A., Maier, W., et al. (2008) Sensorimotor Gating of Schizophrenia Patients Is Influenced by 5-HT2A Receptor Polymorphisms. Biological Psychiatry, 64, 434437. http://dx.doi.org/doi:10.1016/j.biopsych.2008.02.019

[34] Quednow, B.B, Kuhn, K.U., Stelzenmuelle, R., Hoenig, K., Maier, W. and Wagner, M. (2004) Effects of Serotonergic and Noradrenergic Antidepressants on Auditory Startle Response in Patients with Major Depression. Psychopharmacology, 175, 399-406.

[35] Pouzet, B., Andersen, M.P. and Hogg, S. (2005) Effects of Acute Treatment with Antidepressant Drugs on Sensorimotor Gating Deficits in Rats. Psychopharmacology, 178, 9-16. http://dx.doi.org/10.1007/s00213-004-1976-6

[36] Brauer, D., Strobel, A., Hensch, T., Diers, K., Lesch, K.P. and Brocke, B. (2009) Genetic Variation of Serotonin Receptor Function Affects Prepulse Inhibition of the Startle. Journal of Neural Transmission, 116, 607-613. http://dx.doi.org/10.1007/s00702-009-0222-0

[37] Raz, S. and Berger, B.D. (2010) Effects of Fluoxetine and PCPA on Isolation-Induced Morphine Self-Administration and Startle Reactivity. Pharmacology Biochemistry and Behavior, 96, 59-66. http://dx.doi.org/10.1016/j.pbb.2010.04.007

[38] Calabrese, F., Molteni, R. and Riva, M.A. (2011) Antistress Properties of Antidepressant Drugs and Their Clinical Implications. Pharmacology \& Therapeutics, 132, 39-56. http://dx.doi.org/10.1016/j.pharmthera.2011.05.007

[39] Vaswani, M., Linda F.K. and Ramesh, S. (2003) Role of Selective Serotonin Reuptake Inhibitors in Psychiatric Disorders: A Comprehensive Review. Progress in Neuro-Psychopharmacology and Biological Psychiatry, 27, 85-102. http://dx.doi.org/10.1016/S0278-5846(02)00338-X

[40] Siepmann, M., Grossmann, J., Muck-Weymann, M. and Kirch, W. (2003) Effects of Sertraline on Autonomic and Cognitive Functions in Healthy Volunteers. Psychopharmacology, 168, 293-298. http://dx.doi.org/10.1007/s00213-003-1448-4

[41] González, B.G. and Escobar, A. (2002) Neuroanatomía del estrés. Revista Mexicana de Neurociencia, 3, $273-282$.

[42] Faraday, M. (2002) Rat Sex and Strain Differences in Responses to Stress. Physiology \& Behavior, 75, 507-522. http://dx.doi.org/10.1016/S0031-9384(02)00645-5

[43] Chadda, R. and Devaud, L.L. (2005) Differential Effects of Mild Repeated Restraint Stress on Behaviors and GABAA Receptors in Male and Female Rats. Pharmacology Biochemistry and Behavior, 81, 854-863. http://dx.doi.org/10.1016/j.pbb.2005.06.009

[44] Maeng, L.Y. and Milad, M.R. (2015) Sex Differences in Anxiety Disorders: Interactions between Fear, Stress, and Gonadal Hormones. Hormones and Behavior (in Press). http://dx.doi.org/10.1016/j.yhbeh.2015.04.002

[45] Elaković, I, Brkljačić, J. and Matić, G. (2009) Gender-Related Differences in the Effects of Antidepressant Imipramine on Glucocorticoid Receptor Binding Properties and Association with Heat Shock Proteins in the Rat Liver and Kidney. European Journal of Pharmacology, 608, 7-13. http://dx.doi.org/10.1016/j.ejphar.2009.02.038

[46] Kornstein, S.G., Schatzberg, A.F., Thase, M.E., Yonkers, K.A., McCullough, J.P., Keitner, G.I., et al. (2000) Gender Differences in Treatment Response to Sertraline versus Imipramine in Chronic Depression. The American Journal of Psychiatry, 157, 1445-1452. http://dx.doi.org/10.1176/appi.ajp.157.9.1445

[47] Castellano, O., Moscoso, A., Riolobos, A.S., Carro, J., Arji, M., Molina, V., et al. (2009) Chronic Administration of Risperidone to Healthy Rats: A Behavioural and Morphological Study. Behavioural Brain Research, 205, 488-498. http://dx.doi.org/10.1016/j.bbr.2009.08.002

[48] Adams, A.L., Hudson, A., Ryan, C.L. and Doucette, T.A. (2008) Effects of Estrous Stage and Time of Day on Prepulse Inhibition in Female Rats. Journal of Neuroscience Methods, 173, 295-298. http://dx.doi.org/10.1016/j.jneumeth.2008.06.014

[49] Marcondes, F.K., Bianchi, F.J. and Tanno, A.P. (2002) Determination of the Estrous Cycle Phases of Rats: Some Helpful Considerations. Brazilian Journal of Biology, 62, 609-614. http://dx.doi.org/10.1590/S1519-69842002000400008

[50] Pereira-Figueiredo, I., Sancho, C., Carro, J., Castellano, O. and López, D.E. (2014) The Effects of Sertraline Administration from Adolescence to Adulthood on Physiological and Emotional Development in Prenatally Stressed Rats of Both Sexes. Frontiers in Behavioral Neuroscience, 8, 260. http://dx.doi.org/10.3389/fnbeh.2014.00260

[51] Koenig, J.I., Elmer, G.I., Shepard, P.D., Lee, P.R., Mayo, C., Joy, B., et al. (2005) Prenatal Exposure to a Repeated Variable Stress Paradigm Elicits Behavioral and Neuroendocrinological Changes in the Adult Offspring: Potential Re- 
levance to Schizophrenia. Behavioural Brain Research, 156, 251-261. http://dx.doi.org/10.1016/j.bbr.2004.05.030

[52] Kjær, S.L., Wegener, G., Rosenberg, R., Lund, S.P. and Hougaard, K.S. (2010) Prenatal and Adult Stress InterplayBehavioral Implications. Brain Research, 1320, 106-113. http://dx.doi.org/10.1016/j.brainres.2010.01.008

[53] Chung, S., Son, G.H., Park, S.H., Park, E., Lee, K.H., Geum, D., et al. (2005) Differential Adaptive Responses to Chronic Stress of Maternally Stressed Male Mice Offspring. Endocrinology, 146, 3202-3210. http://dx.doi.org/10.1210/en.2004-1458

[54] Santos, J.M., Martinez, R.C.R. and Brandão, M.L. (2006) Effects of Acute and Subchronic Treatments with Fluoxetine and Desipramine on the Memory of Fear in Moderate and High-Intensity Contextual Conditioning. European Journal of Pharmacology, 542, 121-128. http://dx.doi.org/10.1016/j.ejphar.2006.06.019

[55] Ishii, D., Matsuzawa, D., Fujita, Y., Sutoh, C., Ohtsuka, H., Matsuda, S., et al. (2010) Enhancement of Acoustic Prepulse Inhibition by Contextual Fear Conditioning in Mice Is Maintained Even after Contextual Fear Extinction. Progress in Neuro-Psychopharmacology and Biological Psychiatry, 34, 183-188. http://dx.doi.org/10.1016/j.pnpbp.2009.10.023

[56] Pijlman, F.T.A., Herremans, A.H.J., van de Kieft, J., Kruse, C.G. and van Ree, J.M. (2003) Behavioural Changes after Different Stress Paradigms: Prepulse Inhibition Increased after Physical, but Not Emotional Stress. European Neuropsychopharmacology, 13, 369-380. http://dx.doi.org/10.1016/S0924-977X(03)00040-3

[57] Scholes, K.E. and Martin-Iverson, M.T. (2009) Relationships between Prepulse Inhibition and Cognition Are Mediated by Attentional Processes. Behavioural Brain Research, 205, 456-467. http://dx.doi.org/10.1016/j.bbr.2009.07.031

[58] Foley, K.A., MacFabe, D.F., Kavaliers, M. and Ossenkopp, K.-P. (2015) Sexually Dimorphic Effects of Prenatal Exposure to Lipopolysaccharide, and Prenatal and Postnatal Exposure to Propionic Acid, on Acoustic Startle Response and Prepulse Inhibition in Adolescent Rats: Relevance to Autism Spectrum Disorders. Behavioural Brain Research, 278, 244-256. http://dx.doi.org/10.1016/j.bbr.2014.09.032

[59] Conrad, C.D., Jackson, J.L., Wieczorek, L., Baran, S.E., Harman, J.S., Wright, R.L., et al. (2004) Acute Stress Impairs Spatial Memory in Male but Not Female Rats: Influence of Estrous Cycle. Pharmacology Biochemistry and Behavior, 78, 569-579. http://dx.doi.org/10.1016/j.pbb.2004.04.025

[60] Cornwell, B.R., Echiverri, A.M., Covington, M.F. and Grillon, C. (2008) Modality-Specific Attention under Imminent but Not Remote Threat of Shock: Evidence from Differential Prepulse Inhibition of Startle. Psychological Science, 19, 615-622. http://dx.doi.org/10.1111/j.1467-9280.2008.02131.x

[61] Tang, A.C., Jiang, H., Yang, Z., Zhang, Y., Romeo, R.D. and McEwen, B.S. (2011) Converging Influence of Neonatal Novelty Experience and Maternal Self-Stress Regulation on the Plasticity of Offspring Acoustic Startle Response Latency. Behavioural Brain Research, 221, 253-260. http://dx.doi.org/10.1016/j.bbr.2011.03.009

[62] Swerdlow, N.R., Hartman, P.L. and Auerbach, P.P. (1997) Changes in Sensorimotor Inhibition across the Menstrual Cycle: Implications for Neuropsychiatric Disorders. Biological Psychiatry, 41, 452-460.

http://dx.doi.org/10.1016/S0006-3223(96)00065-0

[63] Ellenbroek, B.A., van den Kroonenberg, P.T.J.M. and Cools, A.R. (1998) The Effects of an Early Stressful Life Event on Sensorimotor Gating in Adult Rats. Schizophrenia Research, 30, 251-260. http://dx.doi.org/10.1016/S0920-9964(97)00149-7

[64] Aasen, I., Kolli, L. and Kumari, V. (2005) Sex Effects in Prepulse Inhibition and Facilitation of the Acoustic Startle Response: Implications for Pharmacological and Treatment Studies. Journal of Psychopharmacology, 19, 39-45. http://dx.doi.org/10.1177/0269881105048890

[65] Plappert, C.F., Rodenbücher, A.M. and Pilz, P.K.D. (2005) Effects of Sex and Estrous Cycle on Modulation of the Acoustic Startle Response in Mice. Physiology \& Behavior, 84, 585-594. http://dx.doi.org/10.1016/j.physbeh.2005.02.004

[66] Alemán, C.L., Noa, M. Más, R., Rodeiro, I., Menéndez, R., et al. (2000) Reference Data for the Principal Physiological Indicators in Three Species of Laboratory Animals. Laboratory Animals, 34, 379-385. http://dx.doi.org/10.1258/002367700780387741

[67] Ter Horst, G.J., Wichmann, R., Gerrits, M., Westenbroek, C. and Lin, Y. (2009) Sex Differences in Stress Responses: Focus on Ovarian Hormones. Physiology \& Behavior, 97, 239-249. http://dx.doi.org/10.1016/j.physbeh.2009.02.036

[68] Ordaz, S. and Luna, B. (2012) Sex Differences in Physiological Reactivity to Acute Psychosocial Stress in Adolescence. Psychoneuroendocrinology, 37, 1135-1157. http://dx.doi.org/10.1016/j.psyneuen.2012.01.002

[69] Bourke, C.H., Harrell, C.S. and Neigh, G.N. (2012) Stress-Induced Sex Differences: Adaptations Mediated by the Glucocorticoid Receptor. Hormones and Behavior, 62, 210-218. http://dx.doi.org/10.1016/j.yhbeh.2012.02.024

[70] Burghardt, N.S., Sullivan, G.M., McEwen, B.S., Gorman, J.M. and LeDoux, J.E. (2004) The Selective Serotonin Reuptake Inhibitor Citalopram Increases Fear after Acute Treatment but Reduces Fear with Chronic Treatment: A Comparison with Tianeptine. Biological Psychiatry, 55, 1171-1178. http://dx.doi.org/10.1016/j.biopsych.2004.02.029 
[71] Rossi, D.V., Burke, T.F., McCasland, M. and Hensler, J.G. (2008) Serotonin-1A Receptor Function in the Dorsal Raphe Nucleus Following Chronic Administration of the Selective Serotonin Reuptake Inhibitor Sertraline. Journal of Neurochemistry, 105, 1091-1099. http://dx.doi.org/10.1111/j.1471-4159.2007.05201.x

[72] Goel, N., Innala, L. and Viau, V. (2014) Sex differences in serotonin (5-HT) 1A Receptor Regulation of HPA Axis and Dorsal Raphe Responses to Acute Restraint. Psychoneuroendocrinology, 40, 232-241. http://dx.doi.org/10.1016/j.psyneuen.2013.11.020

[73] Duchesne, A., Dufresne, M.M. and Sullivan, R.M. (2009) Sex Differences in Corticolimbic Dopamine and Serotonin Systems in the Rat and the Effect of Postnatal Handling. Progress in Neuro-Psychopharmacology and Biological Psychiatry, 33, 251-261. http://dx.doi.org/10.1016/j.pnpbp.2008.11.012

[74] Millan, M.J. (2003) The Neurobiology and Control of Anxious States. Progress in Neurobiology, 70, 83-244. http://dx.doi.org/10.1016/S0301-0082(03)00087-X

[75] Sánchez, O., Arnau, A., Pareja, M., Poch, E., Ramírez, I. and Soley, M. (2002) Acute Stress-Induced Tissue Injury in Mice: Differences between Emotional and Social Stress. Cell Stress and Chaperones, 7, 36-46. http://dx.doi.org/10.1379/1466-1268(2002)007<0036:ASITII>2.0.CO;2

[76] Dhabhar, F.S. (2007) Enhancing versus Suppressive Effects of Stress on Immune function: Implications for Immunoprotection and Immunopathology. NeuroImmune Biology, 7, 207-224. http://dx.doi.org/10.1016/s1567-7443(07)00211-6

[77] Patterson, S.M., Krantz, D.S., Gottdiener, J.S., Hecht, G., Vargot, S. and Goldstein, D.S. (1995) Prothrombotic Effects of Environmental Stress: Changes in Platelet Function, Hematocrit, and Total Plasma Protein. Psychosomatic Medicine, 57, 592-599. http://dx.doi.org/10.1097/00006842-199511000-00012

[78] Mischler, K., Fischer, J.E., Zgraggen, L., Kudielka, B.M., Preckel, D. and von Kanel, R. (2005) The Effect of Repeated Acute Mental Stress on Habituation and Recovery Responses in Hemoconcentration and Blood Cells in Healthy Men. Life Sciences, 77, 1166-1179. http://dx.doi.org/10.1016/j.lfs.2005.03.006

[79] von Kanel, R., Preckel, D., Zgraggen, L., Mischler, K., Kudielka, B.M., Haeberli, A., et al. (2004) The Effect of Natural Habituation on Coagulation Responses to Acute Mental Stress and Recovery in Men. Thrombosis and Haemostasis, 92, 1327-1335. http://dx.doi.org/10.1160/th04-04-0223

[80] Robbins, T.W. (2005) Chemistry of the Mind: Neurochemical Modulation of Prefrontal Cortical Function. Journal of Comparative Neurology, 493, 140-146. http://dx.doi.org/10.1002/cne.20717

[81] Arakawa, H., Kodama, H., Matsuoka, N. and Yamaguchi, I. (1997) Stress Increases Plasma Enzyme Activity in Rats: Differential Effects of Adrenergic and Cholinergic Blockades. Journal of Pharmacology and Experimental Therapeutics, 280, 1296-1303.

[82] Chen, S., Xuan, J., Couch, L., Iyer, A., Wu, Y., Li, Q.-Z., et al. (2014) Sertraline Induces Endoplasmic Reticulum Stress in Hepatic Cells. Toxicology, 322, 78-88. http://dx.doi.org/10.1016/j.tox.2014.05.007

[83] Larrey, D. and Ripault, M.-P. (2013) Chapter 25: Hepatotoxicity of Psychotropic Drugs and Drugs of Abuse. DrugInduced Liver Disease. 3rd Edition, Academic Press, Boston, 443-462. http://dx.doi.org/10.1016/B978-0-12-387817-5.00025-X

[84] Glassman, A.H., O’Connor, C.M., Califf, R.M., Swedberg, K., Schwartz, P., Bigger, J.T., et al. (2002) Sertraline Treatment of Major Depression in Patients with Acute MI or Unstable Angina. JAMA, 288, 701-709. http://dx.doi.org/10.1001/jama.288.6.701

[85] Haskell, S.E., Peotta, V.A., Reinking, B.E., Hermann, G.M. and Roghair, R.D. (2013) Impact of Neonatal Sertraline Exposure on the Post-Myocardial Infarction Outcomes of Adult Male Mice. Journal of Cardiovascular Pharmacology, 62, 479-484. http://dx.doi.org/10.1097/FJC.0b013e3182a4db90

[86] Steplewski, Z. and Vogel, W.H. (1986) Total Leukocytes, T Cell Subpopulation and Natural Killer (NK) Cell Activity in Rats Exposed to Restraint Stress. Life Sciences, 38, 2419-2427. http://dx.doi.org/10.1016/0024-3205(86)90611-9

[87] Dhabhar, F.S. (2014) Effects of Stress on Immune Function: The Good, the Bad, and the Beautiful. Immunologic Research, 58, 193-210. http://dx.doi.org/10.1007/s12026-014-8517-0

[88] Jones, B.J. and Blackburn, T.P. (2002) The Medical Benefit of 5-HT Research. Pharmacology Biochemistry and Behavior, 71, 555-568. http://dx.doi.org/10.1016/S0091-3057(01)00745-6

[89] Zanoveli, J.M., Nogueira, R.L. and Zangrossi, H. (2007) Enhanced Reactivity of 5-HT1A Receptors in the Rat Dorsal Periaqueductal Gray Matter after Chronic Treatment with Fluoxetine and Sertraline: Evidence from the Elevated TMaze. Neuropharmacology, 52, 1188-1195. http://dx.doi.org/10.1016/j.neuropharm.2007.01.001

[90] Shelton, R.C. (1994) The Role of Sertraline in the Management of Depression. Clinical Therapeutics, 16, 768-782; Discussion 767.

[91] Kim, S.W., Park, S.Y. and Hwang, O. (2002) Up-Regulation of Tryptophan Hydroxylase Expression and Serotonin Synthesis by Sertraline. Molecular Pharmacology, 61, 778-785. http://dx.doi.org/10.1124/mol.61.4.778 